\title{
Regulation of cancer-related pathways by protein NEDDylation and strategies for the use of NEDD8 inhibitors in the clinic
}

\author{
Naima Abidi and Dimitris P Xirodimas \\ Centre de Recherche de Biochimie Macromoléculaire, UMR5235, 1919 Route de Mende, \\ Montpellier 34293, France
}

Correspondence should be addressed to D P Xirodimas Email dimitris.xirodimas@ crbm.cnrs.fr

\begin{abstract}
Post-translational modification of proteins with ubiquitin and ubiquitin-like molecules (UBLs) controls a vast if not every biological process in the cell. It is not surprising that deregulation in ubiquitin and UBL signalling has been implicated in the pathogenesis of many diseases and that these pathways are considered as major targets for therapeutic intervention. In this review, we summarise recent advances in our understanding of the role of the UBL neural precursor cell expressed developmentally downregulated-8 (NEDD8) in cancer-related processes and potential strategies for the use of NEDD8 inhibitors as chemotherapeutics.
\end{abstract}

\section{Key Words \\ - molecular biology \\ - oncology}

Endocrine-Related Cancer (2015) 22, T55-T70

\section{The neural precursor cell expressed developmentally downregulated-8 pathway and its cross-talk with ubiquitin}

Neural precursor cell expressed developmentally downregulated-8 (NEDD8) is a ubiquitin-like molecule (UBL) sharing $\sim 60 \%$ amino acid identity with ubiquitin. NEDD8 is attached to its substrates in a manner similar to that described for ubiquitination, resulting in the formation of an isopeptide bond linking the terminal carboxyl group of NEDD8 with the $\varepsilon$-amino group of a lysine residue of the substrate (Kumar et al. 1993, Kamitani et al. 1997, Lammer etal. 1998, Liakopoulos etal. 1998, Osaka etal. 1998, Pozo et al. 1998).

The NEDDylation enzymatic cascade is composed of the key enzymatic activities named E1, E2, E3 and deconjugating enzymes. The NEDD8 E1-activating enzyme (NAE) is a heterodimer of APPBP1 and UBA3 corresponding to the $\mathrm{N}$-terminal and C-terminal of the single polypeptide of the ubiquitin E1 respectively (Leyser

http://erc.endocrinology-journals.org DOI: 10.1530/ERC-14-0315 (c) 2015 Society for Endocrinology Printed in Great Britain et al. 1993, Walden et al. 2003a,b). UBE2M (UBC12) and UBE2F are the E2-conjugating enzymes, where multiple E3-ligases promote the conjugation of NEDD8 to its targets (Gong \& Yeh 1999, Huang et al. 2009). With the exception of SMURF1 all identified E3-ligases that promote NEDD8 conjugation belong to the RING family of E3s, including the cullins-associated RBX1/2, the p53-negative regulator MDM2, c-CB1 and the transcriptional co-activator TFB3 (Skowyra et al. 1999, Kamura et al. 1999a,b, Xirodimas et al. 2004, Oved et al. 2006, Yang et al. 2007a,b, Rabut et al. 2011, Xie et al. 2014). The DCN1 protein co-operates with RBX1 to enhance cullin NEDDylation (Kurz et al. 2008, Scott et al. 2011). While NAE is regarded as the only and specific E1 enzyme for NEDD8, biochemical studies provided evidence that the ubiquitin E1 enzyme UBE1 can activate NEDD8 in vitro, however with much lower efficiency compared with ubiquitin (Whitby et al. 1998, Hjerpe et al. 2012a). It has been unclear whether this level of cross-talk between NEDD8 and ubiquitin pathways

Published by Bioscientifica Ltd

This paper forms part of a thematic review section on Ubiquitination and Cancer. The

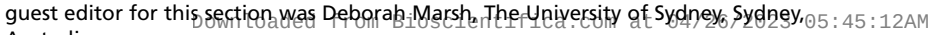
$\begin{aligned} \text { Australia } & \text { via free access }\end{aligned}$ 


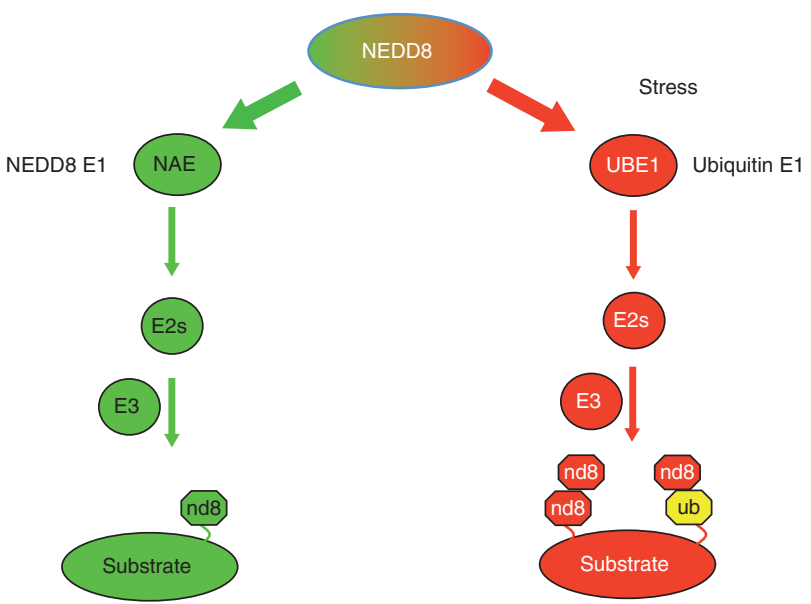

\section{Figure 1}

Modes of NEDD8 conjugation. Activation of NEDD8 by NEDD8-activating enzyme (NAE) defines the canonical NEDDylation pathway under homeostatic conditions. Proteotoxic stress causes an increase in protein NEDDylation that depends on the activation of NEDD8 by the ubiquitin E1 enzyme UBE1. This leads to the formation of poly-NEDD8 and/or hybrid NEDD8-ubiquitin chains on target proteins.

operates in vivo. The role of NEDD8 in homeostasis has been established mainly through regulation of CullinRING-ligases (CRLs; see below). More recent studies have shown that the NEDD8 pathway responds to cellular stress including proteasome inhibition, heat shock and oxidative stress (Xirodimas et al. 2008, Kim et al. 2011, Leidecker et al. 2012, Hjerpe et al. 2012a). Under such stress conditions, a global increase in protein NEDDylation is observed, which does not depend on NAE but rather on the ubiquitin E1 enzyme UBE1. The detection of a thioester bond between NEDD8 and UBE1 provided evidence for the activation of NEDD8 by UBE1 in vivo (Leidecker et al. 2012, Hjerpe et al. 2012a). Proteomic studies designed to discriminate between NEDDylation and ubiquitination sites in vivo identified branched peptides, which strongly indicate the formation of polyNEDD8 and mixed NEDD8-ubiquitin chains upon stress conditions (Xirodimas et al. 2008, Leidecker et al. 2012, Singh et al. 2012; Fig. 1). A similar increase in protein NEDDylation was observed in the brains of hibernating ground squirrels; however, it is not known whether the increase in NEDDylation is UBE1 dependent (Lee et al. 2012). A well-known phenomenon upon the above described stress conditions is the depletion of free ubiquitin, which has been considered as a stress signal (Finley et al. 1987, Finley \& Chau 1991). It appears that this observed decrease in ubiquitin levels is at least part of the mechanism for the activation of NEDD8 by UBE1
(Leidecker et al. 2012, Hjerpe et al. 2012a). This was also supported by the observation that the artificial increase in the levels of NEDD8 by overexpression could lead to NEDD8 conjugation by the ubiquitin pathway (Hjerpe et al. 2012b). Critical issues to be resolved are whether the hybrid NEDD8-ubiquitin chains create a new signal that is specifically detected by cellular factors, alter the recognition of ubiquitin chains by cellular machineries such as the proteasome, or indeed upon depletion of ubiquitin, NEDD8 conjugation acts as a backup mechanism functionally replacing ubiquitin (Singh et al. 2012, 2014).

NEDDylation is a reversible process. The COP9 signalosome is a zinc metalloprotease, which has minimal affinity for NEDD8 but specifically promotes deNEDDylation of cullins (Lyapina et al. 2001, Zhou et al. 2001, Enchev et al. 2012, Birol et al. 2014, Lingaraju et al. 2014). NEDP1 also called as DEN1 or SENP8 due to its sequence similarity to Sumo-specific proteases is a NEDD8-specific protease that can deconjugate NEDD8 from its substrates and it also catalyses the processing of NEDD8 to expose the C-terminal di-glycine motif before its activation by the NAE (Gan-Erdene et al. 2003, Mendoza et al. 2003, Wu et al. 2003, Shen et al. 2005, Rabut \& Peter 2008, Xirodimas 2008). COP9 and NEDP1 are regarded as specific deNEDDylating enzymes. UCH-L3 (Yuh1 in Saccharomyces cerevisiae) is a protease with dual specificity, which can hydrolyse the C-terminus of ubiquitin and NEDD8, and knockout of Uch-L3 in mice causes elevation of NEDD8 protein levels (Wada et al. 1998, Linghu et al. 2002, Kwon et al. 2004). The USP21 deubiquitinating enzyme was also shown to deconjugate NEDD8 upon overexpression in human cell lines, but further structural and biochemical studies have shown a rather specific activity of USP21 towards ubiquitin, so the mechanism behind the effect of USP21 on NEDDylation in vivo is still unclear (Gong et al. 2000, Ye et al. 2011). The Epstein-Barr-virus-encoded member of proteases BPLF1 was shown that in addition to its activity in processing ubiquitin it can also process NEDD8 and de-conjugate NEDD8 from cullins. The de-NEDDylating activity of BPLF1 is required for efficient DNA re-replication to allow synthesis and production of virus DNA (Gastaldello et al. 2010). Additional reported proteases with dual activity towards NEDD8 and ubiquitin include ataxin and the parasite hydrolase PfUCH54 (Artavanis-Tsakonas et al. 2006, Ferro et al. 2007).

\section{Substrates for NEDD8}

The family of cullin proteins is the most established target for NEDD8. In humans, it is composed of seven cullins

Published by Bioscientifica Ltd 
(Cul1, 2, 3, 4A, 4B, 5 and 7), whereas PARC (CUL9) and APC2 (component of the anaphase promoting complex APC) contain a cullin-homology domain (Hochstrasser 1998, Pan et al. 2004, Skaar \& Pagano 2009, Schreiber et al. 2011, Watson et al. 2011, Chang et al. 2014). All cullins are modified with NEDD8, while modification of CUL7 is still controversial (Pan et al. 2004, Skaar et al. 2007). Cullins are scaffold proteins of multicomponent complexes named CRLs that control the stability of a rapidly growing list of proteins with diverse functions including cell cycle regulation, signalling, DNA repair, the response to hypoxia and oxidative stress, centrosome duplication cycle and cytoskeleton dynamics (Watson et al. 2011, Zhao \& Sun 2013). The role of cullin NEDDylation is to enhance the activity of the CRLs and subsequent ubiquitination and degradation of the regulated substrates. CRLs control the stability of a vast variety of targets with established roles in cell cycle progression (p21, p27 and cyclin D/E), DNA replication (CDT1), the oxidative response (NFR2) and the response to hypoxia (HIF1a) (Freed et al. 1999, Karin \& Ben-Neriah 2000, Kondo \& Kaelin 2001, Ohh et al. 2002, Bloom et al. 2003, Hu et al. 2004, Li \& Kong 2009). A study has identified hundreds of potential CRL targets, where functional inactivation of cullins was combined with genetic and proteomic approaches, displaying the diversity of CRLs to control protein stability (Emanuele et al. 2011).

Different models exist for the role of NEDD8 in the regulation of CRL function, including cullin dimerisation, dissociation of cullins from its negative regulator CAND1, conformational changes that bring the E3-RING ligases RBX1/2 in close proximity to the substrate protein, stabilisation of the active CRL state, or control the CRL binding with other E3-ligases and components of the p97 pathway (Duda et al. 2008, Saha \& Deshaies 2008, Merlet et al. 2009, Deshaies et al. 2010, Duda et al. 2011, Bandau et al. 2012, den Besten et al. 2012, Kelsall et al. 2013, Pierce et al. 2013, Wu et al. 2013, Zemla et al. 2013).

While cullins represent the major substrates for NEDD8, additional targets for NEDDylation have been identified. These include transcription factors and co-regulators, signalling receptors, components of the protein synthesis and apoptotic machineries, E3-ligases, histones (Rabut \& Peter 2008, Xirodimas et al. 2008, Wang et al. 2011, Watson et al. 2011). Many of the non-cullin NEDD8 targets are also established ubiquitin substrates and the E3-ligases that promote NEDDylation are also ubiquitin E3-ligases (Rabut \& Peter 2008, Xirodimas 2008). Recent structural studies have revealed an exquisite mechanism that ensures the preferential modification of cullins with NEDD8. It relies on the coordinated action of NEDD8, the RBX1/DCN1 E3-ligases and the substrate itself to preferentially position the NEDD8-loaded UBC12 for cullin modification (Scott et al. 2014). The mechanistic insights revealed in these studies will be important for the determination and characterisation of the pathway used for NEDDylation of non-cullin targets (see below) (NAE or UBE1 NEDD8 activation) and to also understand the mechanism of NEDD8 conjugation by components of the ubiquitin pathway under stress conditions.

\section{Development of NEDD8 inhibitors-MLN4924}

The success of Bortezomib in the clinic highlighted the potential of blocking protein degradation as therapeutic approach. Inhibition of NEDDylation was predicted to satisfy this criterion as NEDD8 can promote diverse protein degradation through activation of CRLs. In addition, expression of NAE, UBC12 and global NEDDylation are found upregulated in a variety of cancers, including lung adenocarcinomas and squamous-cell carcinomas (Chairatvit \& Ngamkitidechakul 2007, Salon et al. 2007, Li et al. 2014a,b, c). Suppression of NEDDylation by either knockdown of NAE or expression of dominant-negative mutants of UBC12 reduced growth rates in the oral carcinoma cell line HSC4 (Chairatvit \& Ngamkitidechakul 2007). Cullins and CRL components are found overexpressed in several types of cancers (Lee \& Zhou 2010, Wang et al. 2014). The well-established examples include the Cul1 F-box adaptor protein FBW7, which is found mutated in $6 \%$ of all cancers, but in some cases of leukaemias or gastrointestinal cancers the mutation rate can be up to 30\% (Welcker \& Clurman 2008). In many cases mutations in FBW7 exist within the substrate binding region, preventing degradation of key regulators of cell proliferation, including cyclin $\mathrm{E}$ as the best characterised FBW7's substrate (Koepp et al. 2001, Welcker et al. 2003, Tetzlaff et al. 2004). Increase in the levels of CUL3 and CUL4A was also associated with tumour progression in breast cancers, but the mechanism for this upregulation is currently unclear (Haagenson $e t$ al. 2012). Increase in mRNA levels of CUL7 was also observed in non-small cell lung carcinoma. Interestingly, CUL7 was proposed to block the apoptotic function of p53 and to cooperate with MYC for anchorage-independent growth, providing insights for the oncogenic properties of CUL7 (Kim et al. 2007). The gene for the human homologue of the NEDD8 E3-ligase DCN1, DCUN1D1/RP42/SCCRO, is localised in chromosome 3, which gets amplified particularly in squamous cell carcinoma. Overexpression

Published by Bioscientifica Ltd. 
of SCCRO was related with transcriptional activation of GLI1, a key regulator of the hedgehog pathway. Targeting the expression of SCCRO or GLI1 in SCCRO overexpressing cells by short hairpin shRNA induces an apoptotic response, providing a possible functional insight for the oncogenic properties of SCCRO (Sarkaria et al. 2006). Collectively, there is a strong correlation between dysfunction in CRL activity and tumourgenesis.

Through an initial screen of chemical libraries and additional medicinal chemistry, MLN4924 was developed as a first in class inhibitor of NAE and the NEDD8 pathway (Soucy et al. 2009). It is an adenosine sulfamate analogue and its action of inhibition is based on a substrate-assisted mechanism (Brownell et al. 2010). NEDD8 and MgATP bind to NAE where NEDD8 is adenylated, before it reacts with the catalytic cysteine in UBA3 to form a NEDD8 thioester bond. A second round of NEDD8 adenylation allows the thioster-linked NEDD8 to be transferred to UBC12 or UBE2F (Walden et al. 2003a). It is during this round that MLN4924 competes for MgATP binding on NAE and is able to attack the thioester-linked NEDD8. The resultant NEDD8-MLN4924 covalent adduct is unable to be transferred on the E2s and subsequently blocks NEDD8 conjugation (Brownell et al. 2010). The IC $_{50}$ of MLN4924 for NAE is single nanomolar compared with micromolar scale for UBE1 or other E1-activating enzymes (>1.5 $\mu \mathrm{M})$, displaying the specificity of MLN4924 towards NAE (Soucy et al. 2009). MLN4924 was shown to be effective in reducing growth and inducing apoptosis in a variety of tumour cell lines and tumour xenografts, suggesting a broad anti-tumour spectrum for NEDD8 inhibitors (Soucy et al. 2010). MLN4924 has entered cancer clinical trials and more details can be found in http://clinicaltrials.gov/ct2/ results?term $=$ MLN4924\&Search $=$ Search)

Importantly, recent studies have demonstrated that NAE is the key target of MLN4924 in vivo. In tumour cell lines and xenografts, treatment-emerging resistance was observed for MLN4924. Sequencing in the resistant lines identified heterologous mutations in UBA3 (predominantly A171T) within the MgATP-binding cleft where MLN4924 also binds (Milhollen et al. 2012, Toth et al. 2012, Xu et al. 2014). These data strongly suggest that the observed biological effects in MLN4924-treated cells are primarily due to NAE inhibition.

\section{Effects of NEDD8 inhibition through CRLs inactivation}

Treatment of several tumour cell lines with MLN4924 produced a rapid (within $5 \mathrm{~min}$ ) decrease in cullin
NEDDylation and increase in several known CRL targets, indeed validating MLN4924's action in blocking protein NEDDylation downstream of NAE (Soucy et al. 2009). Although many CRL targets are involved in cell cycle regulation at different phases, the predominant effect of MLN4924 is an initial S-phase arrest. This is due to accumulation of CDT1, a replication licensing factor that is degraded by CUL4 ${ }^{\mathrm{Cdt} 2}$ - or CUL1 ${ }^{\mathrm{Skp} 2}$-based CRLs to allow entry into mitosis (Zhong et al. 2003, Higa et al. 2006, Jin et al. 2006, Sansam et al. 2006, Senga et al. 2006, Kim \& Kipreos 2007). In the absence of CDT1 degradation, the resulting DNA re-replication in the absence of mitosis causes the induction of the DNA damage response and apoptosis (Kim \& Kipreos 2007, Soucy et al. 2009). A different mechanism for MLN4924-induced apoptosis was proposed in activated B-cell-like diffuse large B-cell lymphoma (DLBCL). It is due to lack of degradation of I $\kappa \mathrm{B} \alpha$ and subsequent inhibition of $\mathrm{NF} \kappa \mathrm{B}$, a pathway, which DLBCL growth depends on (Milhollen et al. 2010, Swords et al. 2010, Duncan et al. 2012).

Induction of apoptosis is not the sole mechanism responsible for the growth suppressive effects of MLN4924. Treatment of several tumour cell lines with low doses of MLN4924 (>100 nM) induces irreversible senescence in a p21-dependent but p53- and Rb-independent manner (Jia et al. 2011). In addition, inhibition of NEDDylation by MLN4924 activates autophagy, a process of intracellular proteolysis that delivers cytoplasmic components to lysosomal degradation (Luo et al. 2012a,b, Yang et al. 2012a,b, Zhao et al. 2012, Hurley \& Schulman 2014, Schreiber \& Peter 2014). Autophagy can act both as tumour suppressor and as a survival signal in established tumours (Yang et al. 2011). The activation of autophagy by MLN4924 is due to accumulation of Deptor and HIF1 $\alpha$, substrates of $\mathrm{Cul} 1^{\beta \mathrm{TrCP}}$ and $\mathrm{CUL} 2^{\mathrm{VHL}}$ ligases (Zhao et al. 2012). The downstream effect is the inhibition of the mTORC1 pathway, which supressess autophagy. The activation of autophagy was observed in multiple tumour cell lines treated with MLN4924 and importantly, autophagy induction protected cells against the apoptotic effects of MLN4924 (Zhao et al. 2012). More recently, MLN4924 has been shown to inhibit tumour angiogenesis and tumourgenesis in melanoma or $\mathrm{KRAS}^{\mathrm{G} 12 \mathrm{D}}$-driven lung tumours in mice model systems. At least partially, this is due to accumulation of the cell cycle inhibitor p27 (Tan et al. 2013) or inhibition of the NFкB and mTOR pathways respectively (Li et al. 2014a,b,c). Similar anti-tumour effects of MLN4924 were observed in both in vitro and in vivo model systems of pancreatic cancer, resulting in suppression of tumour growth and metastasis (Yao et al.

Published by Bioscientifica Ltd. 
2014). In this system, the anti-tumourgenic effects of MLN4924 are due to the accumulation of RhoA, a member of the Rho GTPase family that is involved in the control of cellular migration (Chen et al. 2009, Leck et al. 2010). The assessment for the potential clinical effects of MLN4924 has so far been focussed on CRL inhibition and accumulation of CRL targets (Soucy et al. 2010, Swords et al. 2010). Another emerging concept is that inhibition of cullin NEDDylation can also induce anti-apoptotic or tumourgenic responses (see also below) that could modulate the efficacy of MLN4924 in clinic. For example, MLN4924 causes the stabilisation of proteins such as the NRF2 transcription factor, which controls the induction of anti-oxidant genes. NRF2 degradation is mediated by a CUL3 $^{\text {Keap } 1}$ CRL and is prevented in $\sim 30 \%$ of lung cancers either due to mutation in KEAP1 or NRF2 (Itoh et al. 1999, Cullinan et al. 2004, Lee \& Zhou 2010).

\section{Inhibition of NEDDylation of non-cullin targets}

Many of the reported non-cullin NEDD8 targets include key cell cycle regulators and tumour suppressors. The VonHipple-Lindau (VHL) and p53 tumour suppressors were identified as the first non-cullin substrates (Stickle et al. 2004, Xirodimas et al. 2004). VHL is a component of a Cul2-based E3-ligase that controls the stability of HIF1 $\alpha$ upon hypoxic conditions (Ohh 2006). NEDDylation of VHL promotes its binding to fibronectin and prevents the incorporation of VHL within a CRL2 complex (Stickle et al. 2004, Russell \& Ohh 2008). The interaction of VHL with fibronectin is important in tumour progression, as all VHL tumour-derived mutants are deficient in fibronectin interaction (Russell \& Ohh 2008). This predicts that inhibition of NEDDylation would predispose cells to increased tumourgenesis through lack of interaction of VHL with fibronectin. The studies also proposed a role of NEDD8 as regulatory switch that can selectively control the VHL incorporation either within a CRL2 complex or to bind to fibronectin, defining two distinct functional outcomes (Fig. 2).

\section{NEDD8 and transcriptional activity regulation}

\section{p53 and TAp73}

An emerging role for NEDDylation of non-cullin targets is the control of transcriptional activity. Several studies have implicated the NEDD8 pathway as regulator of the p53 tumour suppressor and its homologue TAp73. Direct NEDDylation of p53 and TAp73 inhibits their
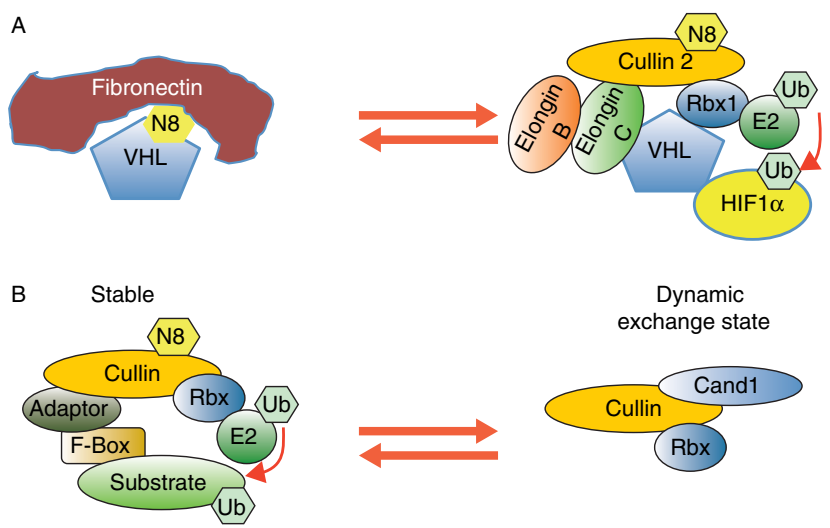

Stable
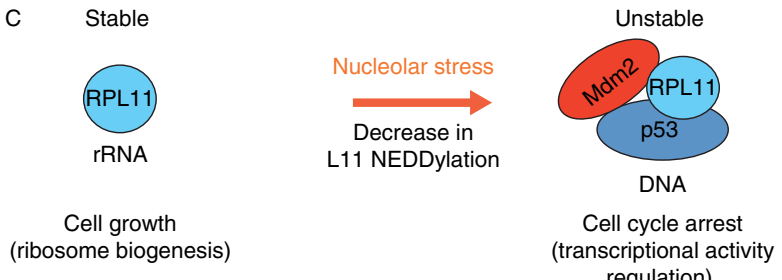

Figure 2

NEDD8 controls protein complex formation. (A) NEDDylation of VonHippel-Lindau (VHL) promotes binding of VHL to fibronectin excluding its incorporation within a CRL2 complex. (B) Modification of cullins with NEDD8 stabilises the active Cullin-RING-ligase (CRL) complex containing an F-box protein bound to its substrate. DeNEDDylation allows the reshuffling of the complex (dynamic state) through binding of CAND1 that acts as an exchange factor allowing the incorporation of new F-box proteins and substrates. (C) Under homeostatic conditions ribosomal proteins (RPL11) are associated with rRNA for ribosome biogenesis. Upon nucleolar stress, decrease in RPL11-NEDDylation allows the incorporation of RPL11 in complexes at transcriptional sites controlling gene expression.

transcriptional activity (Xirodimas et al. 2004, Watson et al. 2006). The MDM2 E3-ligase, which is a common negative regulator for $\mathrm{p} 53$ and TAp73, promotes NEDDylation through direct binding to the substrates (Xirodimas et al. 2004, Watson et al. 2006). FBX011, an F-box protein and a component of CUL1-CRL preferentially promotes p53 NEDDylation but not ubiquitination and inhibits p53 transcriptional activity (Abida et al. 2007). The required lysines for p53 NEDDylation (K370, K372, K373 for MDM2 and $\mathrm{K} 320, \mathrm{~K} 321$ for $\mathrm{FBX011)}$ are also reported sites for p53 ubiquitination, suggesting mutual exclusion or possibly cooperation between NEDD8 and ubiquitin for controlling p53 function (Xirodimas et al. 2004). Despite the close sequence similarity between NEDD8 and ubiquitin, these molecules differentially control p53 localisation. A fusion of C-terminal p53 to NEDD8 causes a nuclear p53 localisation, whereas a similar fusion with ubiquitin is found exclusively in the cytoplasm (Brooks \& Gu 2006, Carter et al. 2007). Evidence for a physiological

Published by Bioscientifica Ltd. 
role for such differential role of NEDD8 and ubiquitin comes from studies on NEDD8 Ultimate Buster 1 (NUB1) and the TIP60 acetyltransferase. NUB1 was identified as a NEDD8 interacting protein and contains two UBA domains (Kamitani et al. 2001, Kito et al. 2001). Expression of NUB1 decreases p53 NEDDylation and promotes p53 mono-ubiquitination, which creates a nuclear export signal and cytoplasmic localisation of p53 (Liu \& Xirodimas 2010). TIP60 expression causes a preferential decrease in p53 NEDDylation but not ubiquitination (Dohmesen et al. 2008). The localisation of TAp73 is also controlled by NEDD8, but in contrast to p53 it promotes its cytoplasmic localisation (Watson et al. 2006). Whether NEDD8 specifically controls binding of p53 and TAp73 with nuclear or cytoplasmic anchoring factors is not yet known.

Another level of control of p53 function was revealed through the identification of ribosomal proteins as NEDD8 targets (Xirodimas et al. 2008). Ribosomal proteins have emerged as critical regulators of the p53 pathway. Under normal growth conditions ribosomal proteins rapidly enter the nucleolus as part of the ribosome biogenesis process for the production of the small and large subunits of the ribosome. However, conditions that mainly block transcription in the nucleolus, including nutrient starvation or treatment with low doses of the chemotherapeutic drug actinomycin $\mathrm{D}$, cause the so-called nucleolar or ribosomal stress. This is manifested by the relocalisation of ribosomal proteins from the nucleolus to the nucleoplasm. Under these conditions, ribosomal proteins are able to bind and inhibit the activity of MDM2, which under unstressed conditions targets p53 for degradation (Zhang \& Lu 2009, Boulon et al. 2010, Golomb et al. 2014, Vlatkovic et al. 2014). NEDDylation of RPL11 and RPS14 was shown to control the above signalling event (Sundqvist et al. 2009, Zhang et al. 2014). Nucleolar stress conferred by actinomycin D causes a decrease in RPL11 NEDDylation that allows RPL11 relocalisation from the nucleolus to the nucleoplasm and 553 activation. The MDM2 E3-ligase and the myeloma overexpressed 2 (MYEOV2) proteins were shown as cellular factors that promote or decrease RPL11-NEDDylation respectively (Sundqvist et al. 2009, Ebina et al. 2013). Similarly to RPL11, MDM2 promotes NEDDylation of RPS14 and it is required for its nucleolar localisation (Zhang et al. 2014). The human coilin-interacting nuclear ATPase protein (hCINAP), a protein essential for Cajal body formation, directly binds to RPS14 and inhibits RPS14 NEDDylation due to the recruitment of NEDP1 (Zhang et al. 2014). Mechanistically, at least for RPL11, the observed relocalisation upon stress is accompanied with the recruitment of RPL11 to the transcription sites of p53-regulated genes, facilitating the recruitment of the p300 transcriptional co-activator and p53 activation (Mahata et al. 2012).

The models derived from the studies on VHL and cullin NEDDylation propose that NEDD8 controls the substrate incorporation within different complexes or stabilises the active state of a complex respectively (Russell \& Ohh 2008, Pierce et al. 2013). Similarly, NEDDylation may also control the differential incorporation of ribosomal proteins either within the ribosome biogenesis pathway (unstressed conditions) or within transcription factor complexes (nucleolar stress conditions) (Fig. 2). Inhibition of protein NEDDylation may cause the re-organisation of multicomponent complexes with distinct functional outcomes (Fig. 2).

Several cullins have also been implicated in negatively regulating p53 stability and function, either through direct binding to p53 (CUL7, PARCc) and cytoplasmic sequestration, through binding to MDM2 (CUL4A/B) or viral proteins (CUL2, 5) that facilitate p53 degradation (Querido et al. 2001, Nikolaev et al. 2003, Ali et al. 2004, Nag et al. 2004, Andrews et al. 2006, Banks et al. 2006, Sato et al. 2009, Thirunavukarasou et al. 2014).

The key biological outcome of all the above regulatory processes is the inhibition of $\mathrm{p} 53$ function by the NEDD8 pathway. Initial studies suggested that the biological effect of NEDD8 inhibition by MLN4924 is independent of the p53 status (Soucy et al. 2009). However, further studies showed that the p53 pathway could affect the biological outcome of NEDD8 inhibition in tumour cells (Lin et al. 2010, Blank et al. 2013). Interestingly, knockdown of p53 in MCF7 breast cancer cells facilitated the apoptotic response to MLN4924 treatment, suggesting that p53 activation may indeed protect cells against the apoptotic effect induced by NEDD8 inhibition (Lin et al. 2010). It is therefore important to establish the mechanism for the cytoprotective effect of p53, as inhibitors of p53 function could promote the MLN4924-induced apoptotic effect in tumours containing WT p53, which account for $50 \%$ of all cancer cases (Muller \& Vousden 2014).

\section{E2F1}

The theme of transcriptional repression by NEDD8 was further expanded with studies on the NEDDylation of the transcription factor E2F1. The E2F family of eight members of transcription factors has an essential role in cell cycle progression and the G1 to $S$ phase transition. E2F can also control apoptosis as in response to DNA damage

Published by Bioscientifica Ltd. 
induces expression of proapoptotic genes such as p73, APAF1, caspases (Biswas \& Johnson 2012). NEDDylation represses the transcriptional activity of E2F1, which is relieved upon DNA damage and the action of the NEDP1 deNEDDylating enzyme (Loftus et al. 2012, Aoki et al. 2013). This allows the interaction of E2F1 with the co-activator Microcephalin (MCHP1) that is required for p73 induction (Aoki et al. 2013). Interestingly, the site of E2F1 NEDDylation (K185) is also methylated, providing another example of a possible interplay between NEDDylation and additional post-translational modifications (Loftus et al. 2012).

\section{NF $\kappa$ B}

NEDD8 also controls the function of NFKB by modifying the regulators of the pathway. The NEDDylation of the breast cancer-associated protein 3 (BCA3) inhibits $\mathrm{NF \kappa B}$ activity in the nucleus through recruitment of the SIRT1 deacetylase (Gao et al. 2006). More recent studies have shown that the TRIM40 and BRCA1-associated protein 2 (BRAP2) E3-ligases could impact on the activity of NFкB. TRIM40, a member of the Tripartite motif (TRIM) family of RING finger proteins, was found to interact with NEDD8 in a yeast two-hybrid screen (Noguchi et al. 2011). A role for TRIM40 in controlling NFKB function was then revealed, as TRIM40 interacts with IKK $\gamma$, a component of the IKK complex that activates NFאB. TRIM40 was shown to promote NEDDylation of IKK $\gamma$ and to repress NFKB function. K63-linked or linear poly-ubiquitination activates IKK and NFKB and therefore TRIM40-mediated NEDDylation of IKK $\gamma$ may oppose this activation signal (Noguchi et al. 2011). As TRIM40 expression is significantly reduced in gastrointestinal carcinomas, it will be interesting to determine the level of IKK $\gamma$ NEDDylation in these tumours. BRAP2 was also identified as a NEDD8 interacting protein in a yeast two-hybrid screen and to also bind CUL1 within the Cul1 ${ }^{\beta \operatorname{Trcp}}$ complex that activates $\mathrm{NF} \kappa \mathrm{B}$. Interestingly, BRAP2 is NEDDylated in a lysine that is within a motif similar to that of cullin NEDDylation (Takashima et al. 2013). The role of NEDD8 in BRAP2 function is not clear. However, overexpression or knockdown of BRAP2 leads to inhibition of NFKB nuclear translocation and activation, suggesting that BRAP2NEDDylation or other post-translational modifications may control BRAP2 complex formation with components of the NFkB pathway (Takashima et al. 2013). Depending on cellular conditions NFאB can act as an oncogene or tumour suppressor (Perkins 2012). Differential regulation of components and complex formation within the NFKB pathway by post-translational modifications such as NEDDylation could provide the required elements for such functional switch. As our knowledge on NFKB function as an oncogene or tumour suppressor is growing, appropriate cancer model systems will be available to test the effect of NEDD8 inhibitors on NFKB functional switch and tumour suppression.

\section{Membrane receptors}

An opposing function of NEDD8 in controlling signalling through transmembrane tyrosine receptors was proposed. The epidermal-growth-factor-receptor (EGFR) and the transforming growth factor $\beta$ type II receptor (TRRII) initiate signalling events upon binding to their respective ligands that control a plethora of biological processes related to cancer, including cell proliferation, fate determination and apoptosis (Massaguéet al. 2000). Receptor turnover is controlled by ubiquitination and in the case of EGFR and TBRII, the c-CBL E3-ligase promotes ubiquitination and degradation of the receptors (Oved et al. 2006, Zuo et al. 2013). As a common emerging function of RING E3-ligases, c-CBl can also promote NEDDylation of both receptors but with opposing outcomes. Upon ligand stimulation, c-CBL promotes EGFR NEDDylation, which further enhances EGFR ubiquitination and clathrin-mediated endocytosis for lysosomal degradation (Oved et al. 2006). However for TBRII, c-CBLmediated NEDDylation at $\mathrm{K} 556$ and $\mathrm{K} 567$ protects the receptor from ubiquitination. This is due to the preferential targeting of the receptor for endocytosis to EEA1positive early endosomes rather than to caveolin-positive compartments, where TBRII is ubiquitinated and degraded (Zuo et al. 2013). c-CBL mutations have been identified in leukaemia patients and one such identified mutation (H398L) severely impaired the activity of c-CBL to NEDDylate TBRII but also to ubiquitinate EGFR (Zuo et al. 2013).

The anti-diglycine antibody that enriches for peptides modified either by ubiquitin, NEDD8 or the Ubl ISG15 has been used in a recent proteomic approach to identify new targets for the Fanconi anaemia core complex (FANC) E3-ligase. The studies confirmed that fanconi anaemia complementation group D2 protein (FANCD2) is a major target for the FANC core complex (see also below). In addition, di-glycine peptides derived from the chemokine membrane receptor CXCR5 were significantly reduced in cells deficient for FANCA (one of the FANC partners) compared with cells corrected for FANCA expression. Further analysis showed that CXCR5 is NEDDylated but

Published by Bioscientifica Ltd. 
not ubiquitinated on lysine 339. The role of CXCR5 NEDDylation is to promote the membrane localisation of the receptor and is required for cell motility, a process controlled by CXCR5 in B-lymphocytes upon its ligand binding (Renaudin et al. 2014).

\section{Histone modification and DNA damage response}

There is also evidence to support a non-cullin role of NEDD8 in controlling the DNA damage response and apoptosis. Modification of histone $4(\mathrm{H} 4)$ and histone $\mathrm{H} 2 \mathrm{~A}$ with NEDD8 is involved in the DNA damage response (Ma et al. 2013, Li et al. 2014a,b,c). RNF111 and RNF168 RING E3-ligases are involved in a complex way to control NEDDylation of $\mathrm{H} 4$ and H2A. DNA damage causes an increase in H4 NEDDylation mediated by RNF111, and a decrease in H2A-NEDDylation, which is physiologically mediated by RNF168. Under these conditions, RNF168 recognises the NEDD8 chains on $\mathrm{H} 4$, whereas the decrease in H2A-NEDDylation allows its ubiquitination. Both events are required for the subsequent recruitment of $\gamma-\mathrm{H} 2 \mathrm{AX}$ and BRAC1 to sites of DNA damage (Ma et al. 2013, Li et al. $2014 a, b, c)$. This intricate regulation of histone NEDDylation and ubiquitination may represent another example of cooperation between these modifiers to reorganise complex formation and allow, for example, the redistribution of E3-ligases such as RNF168 from $\mathrm{H} 2 \mathrm{~A}$ to $\mathrm{H} 4$.

In vivo siRNA screen of individual deubiquitinating enzymes in the developing eye of Drosophila, expressing antagonists for the inhibitors of apoptosis (IAPs) identified three different deNEDDylating enzymes as potential apoptosis regulators. NEDP1 (DEN1, SENP8) was one of the identified enzymes and its knockdown suppressed apoptosis. Further characterisation showed that the apoptosis executors Drice and caspase 7 are NEDDylated by the E3-ligases DIAP and XIAP, respectively, inhibiting their function. NEDP1 can reverse this effect by removing NEDD8, facilitating the execution of apoptosis (Broemer et al. 2010). While subsequent studies challenged the direct NEDDylation of caspase 7, it appears that NEDD8 can suppress apoptosis through cullin-independent mechanisms using NEDP1 as a regulator of the process (Broemer et al. 2010, Nagano et al. 2012). The above recent studies highlight potential new roles for NEDD8 in controlling cancer-related processes such as the DNA damage response and induction of apoptosis.

The Hu antigen $\mathrm{R}(\mathrm{HuR})$ is an RNA-binding protein enhancing the stability of multiple mRNAs encoding proteins with important roles in cell cycle and proliferation or tumour cell growth. HuR is found overexpressed in a wide variety of tumours, and there is a close correlation between HuR overexpression and tumourgenesis. NEDDylation of HuR, mediated by the MDM2 E3-ligase, protects HuR stability. Inhibition of NEDDylation either by siRNA knockdown of NEDD8 or UBC12 causes a decrease in HuR levels in colon and human liver cancer cell lines that overexpress HuR. The effect of NEDD8 in HuR stability is related with HuR subcellular localisation as NEDDylation promotes HuR nuclear localisation and protection from degradation (Embade et al. 2012). Therefore, similarly to what is observed for ribosomal proteins, NEDD8, in some cases, can protect targets from degradation, potentially by competing for ubiquitination sites or altering the rates of proteasomal degradation of substrates that can be simultaneously NEDDylated and ubiquitinated.

\section{E3-ligases}

The studies on the NEDDylation of non-cullin substrates had so far identified RING E3-ligases as the mediators of NEDD8 conjugation (Rabut \& Peter 2008, Xirodimas 2008). Recent evidence has strongly supported that the HECT E3ligase Smad ubiquitination regulator factor 1 (SMURF1) can also promote NEDDylation (Xie et al. 2014). In a yeast twohybrid screen using SMURF1 as bait, NEDD8 was identified as potential interactor. A strong correlation between the expression of SMURF1 and components of the NEDD8 machinery in colorectal cancers prompted the authors to test the interaction of SMURF1 with NEDD8 and UBC12. A series of biochemical and biological studies revealed that SMURF1 binds to UBC12 promoting auto-NEDDylation. Interestingly, the authors identified CYS426 as potential catalytic residue for auto-NEDDylation distinct from its ubiquitination catalytic site CYS699. Reminiscent to the role of NEDD8 in CRL activity regulation, SMURF1 NEDDylation increases its ubiquitin ligase activity towards substrates and to itself. The phenomenon is conserved in $S$. cerevisiae, as the SMURF1 homologue RSP5 is similarly controlled by NEDDylation. However, RSP5 uses the same catalytic site CYS777 both for NEDDylation and ubiquitination. Importantly, the NEDD8 catalytic mutant of SMURF1 (C426A) has lost the ability to promote tumour formation in both in vitro and in vivo colorectal xenograft models. The regulatory role of NEDD8 for SMURF1 activity may be particularly important for colorectal cancers where SMURF1 is found to be overexpressed (Xie et al. 2014).

Additional NEDD8 targets with implications in neurodegenerative diseases include the amyloid precursor protein

Published by Bioscientifica Ltd. 
(APP) intracellular domain (AICD), the E3-ligase Parkin and the Pink1 kinase. Processing of the transmembrane protein APP creates a C-terminal AICD fragment, which translocates into the nucleus to control transcription by the FE65 and TIP60 transcriptional co-regulators. NEDDylation of APP was shown to occur at the AICD fragment and inhibited its interaction with FE65 and TIP60 (Lee et al. 2008). Parkin a RING in between RING E3-ligase and the Pink1 kinase play important roles in mitochondria maintenance and are found mutated in familial forms of Parkinson's disease. Parkin was shown to be NEDDylated, which increased Parkin ubiquitin E3-ligase activity towards itself and to its substrates (Choo et al. 2012, Um etal. 2012). NEDDylation of PINK1 increased the stability of the PINK1 55 kDa fragment, a processed form of PINK1 that is found in the cytoplasm. Importantly, NEDDylation of Parkinson's Disease was shown in extracts from human brains of PD patients, and treatment of cells with PD-related neurotoxins decreased NEDDylation of both Parkin and Pink1 (Choo et al. 2012). These studies may have implications in understanding Parkin and Pink1 regulation in neurodegeneration. However, as a potential function of Parkin as a tumour suppressor is revealed, these findings could expand Parkin's regulatory mechanisms to cancer-related pathways (Picchio et al. 2004, Fujiwara et al. 2008, Alderton 2010).

\section{Potential strategies for the use of NEDD8 inhibitors in cancer therapy}

The promising pre-clinical studies for MLN4924 have demonstrated the potential of NEDD8 inhibitors as chemotherapeutics (Table 1). They also provide the proof of principle to develop E1 inhibitors for other UBL E1 enzymes, such as SUMO or autophagy system, for which their role in cancer-related processes is well established. Common issues for compounds that enter into clinical trials include the potential development of resistance and their use as single agents or in combination therapy. The studies in tissue culture and xenograft model systems have indeed showed that resistance to MLN4924 is a highly anticipated outcome (Milhollen et al. 2012, Toth et al. 2012, Xu et al. 2014). These results are critical as not only demonstrate that the observed anti-tumour effects of MLN4924 depend primarily on its target, NAE, but also raise the necessity to develop new compounds that potentially will overcome resistance. Targeting the E2-conjugating enzymes or E3-ligases could be an interesting approach. For example, allosteric inhibitors for the ubiquitin E2-conjugating enzyme Cdc34, which is the primary ubiquitin E2 for CRLs, have been developed and similarly to NAE inhibitors they block CRL activity and cause accumulation of CRL targets (Ceccarelli et al. 2011). The unique N-terminus of the NEDD8 E2-conjugating enzyme UBC12, which provides an additional and specific interaction surface for NAE binding may also represent an interesting target to specifically block NEDD8 conjugation (Huang et al. 2004, Scott et al. 2011). Combination of MLN4924 with radiation or chemotherapeutics may also be an alternative or additional therapeutic approach. MLN4924 was shown to sensitise breast, pancreatic and lung cancer cells to ionising radiation. The combination dramatically increased the proportion of cells in the

Table 1 Potential combination approaches for MLN4924

\begin{tabular}{|c|c|c|c|}
\hline Agent & Target & Tumour type & $\begin{array}{l}\text { Targets of MLN4924 in } \\
\text { combination therapy }\end{array}$ \\
\hline Ionising radiation & $\begin{array}{l}\text { DNA double strand } \\
\text { breaks }\end{array}$ & $\begin{array}{l}\text { Breast, pancreatic, lung } \\
\text { cancer }\end{array}$ & $\begin{array}{l}\text { p21 (breast cancer); } \\
\text { wee1, cdt1 } \\
\text { (pancreatic, } \\
\text { lung cancers) }\end{array}$ \\
\hline Cisplatin & DNA crosslinker & Ovarian cancer & FANCD2 \\
\hline Mitomycin C & DNA crosslinker & Melanoma & Re-replication, cdt1? \\
\hline $\begin{array}{l}\text { Non-genotoxic } \\
\text { (TRAIL) }\end{array}$ & Death receptors & $\begin{array}{l}\text { Head and neck squamous } \\
\text { cell carcinoma }\end{array}$ & $\begin{array}{l}\text { FLICE-inhibitory } \\
\text { protein }\end{array}$ \\
\hline Pifithrin & p53 inhibitor & Tumours with WT p53 & $?$ \\
\hline $\begin{array}{l}\text { Proteasome } \\
\text { inhibitors }\end{array}$ & 26S proteasome & $?$ & $?$ \\
\hline PYR-41 & $\begin{array}{l}\text { UBE1 (ubiquitin } \\
\text { activating enzyme) }\end{array}$ & $?$ & $?$ \\
\hline Autophagy inhibitors & Atg7? & $?$ & $?$ \\
\hline
\end{tabular}

References
$\begin{aligned} & \text { Wei et al. (2012), Yang et al. } \\ & (2012 a, b)\end{aligned}$
Kee et al. (2012), Jazaeri et al.
(2013)
Garcia et al. (2014)
Zhao et al. (2011)
Komarov et al. (1999), Lin et al.
(2010), Blank et al. (2013)
Kim et al. (2011), Leidecker et al.
(2012), Hjerpe et al. (2012a)
Yang et al. (2007a,b), Leidecker
et al. (2012), Hjerpe et al.
(2012b)
Zhao et al. (2012)


G2/M phase, which was associated with the observed sensitisation. Mechanistically, the effects appear to be due to the accumulation of CRL substrates cyclin-dependent kinase inhibitor p21 (breast cancer), or the wee1 kinase and the replication licensing factor CDT1 (pancreatic, lung cancers) (Wei et al. 2012, Yang et al. 2012a,b). In other studies, MLN4924 showed moderate activity in ovarian cancer cell lines as single therapy, but an additive effect was observed upon the combination of MLN4924 with the platinum-containing chemotherapeutic cisplatin. Importantly, the MLN4924-cisplatin combination was effective in ovarian cancer cell lines derived from patients who exhibited poor response to cisplatin alone, providing a potential new therapeutic approach for these cancers (Jazaeri et al. 2013). MLN4924 was shown to suppress cisplatin-induced mono-ubiquitinatination of FANCD2, a key step in the repair of DNA interstrand cross-linkages (ICLs) produced by cisplatin (Kee et al. 2012). These studies provide insights on the mechanism used for the observed sensitisation of MLN4924-treated cancer cells to DNA ICLs-inducing agents. Similar exciting results were obtained from the combination of MLN4924 with another DNA-alkylating chemotherapeutic, mitomycin C. In several tumour cell lines and in A375 melanoma xenografts, a synergy was observed between MLN4924 and mitomycin $\mathrm{C}$, which is dependent on intact DNA damage and repair pathways, comprising ATR, BRAC1/2 and transcription coupled-nucleotide excision repair (TC-NER) (Garcia et al. 2014).

Another combination strategy for MLN4924 was proposed in head and neck squamous cell carcinoma (HNSCC) model systems. MLN4924 efficiently decreased the viability of several tested HNSCC cell lines as single agent, but its combination with the tumour necrosis factor-related apoptosis inducing signal (TRAIL/Apo2L) had a synergistic effect on induced apoptosis. At the molecular level, MLN4924 causes the degradation of the cellular FLICE-inhibitory protein (c-FLIP), a truncated form of caspase 8 that acts in a dominant-negative manner to block caspase 8 activation induced by TRAIL (Zhao et al. 2011). Combination of MLN4924 with non-genotoxic inducers of apoptosis may prove an attractive therapeutic approach, as non-genotoxic agents are generally less toxic to healthy cells compared with DNA damaging agents.

As inhibition of NEDDylation by MLN4924 can also induce responses that protect cells against treatmentinduced apoptosis, inhibitors of such pathways may enhance the anti-tumour effects of MLN4924. Using p53 inhibitors such as pifithrin could prevent the observed cytoprotective effect of p53 activation upon MLN4924 treatment (Komarov et al. 1999). Similarly, inhibitors of the autophagy pathway may also sensitise cells to MLN4924. Such an approach will be also part of a growing concept for an extensive cross-talk between ubiquitin and UBLs that is observed in different cellular conditions. The NEDD8-ubiquitin cross-talk is at the level of CRL activation and protein ubiquitination and through activation of NEDD8 by the ubiquitin E1 enzyme UBE1. The later may be relevant should MLN4924 is combined with proteasome inhibitors in the clinic, as proteasome inhibition increases protein NEDDylation through UBE1 and is insensitive to MLN4924 treatment (Leidecker et al. 2012, Hjerpe et al. 2012a). This also raises the question whether MLN4924 should be combined with inhibitors of UBE1 such as PYR-41 or it will prove too toxic? (Yang et al. 2007a,b, Lane 2012).

Our knowledge on the complexity within the ubiquitin and UBL pathways and diversity of the regulated processes is rapidly growing. Protein NEDDylation is clearly emerging as an important regulator of several cancer-associated pathways with either pro- or antitumourgenic potential. A complete understanding of the spectrum of regulated processes and mechanisms of control of the NEDD8 pathway will help the potential use of NEDD8 inhibitors in the clinic as a single agent or in combination with other therapeutics.

\section{Declaration of interest}

The authors declare that there is no conflict of interest that could be perceived as prejudicing the impartiality of this review.

\section{Funding}

This review did not receive any specific grant from any funding agency in the public, commercial or not-for-profit sector.

\section{Acknowledgements}

The authors are grateful to the anonymous reviewers and Dr Radoslav I Enchev for critical reading of the manuscript and their constructive comments. Research in DPX laboratory is supported by the Atip/Avenir fellowship, ANR (National Agency for Research), FRM (Fondation pour la Recherche Medicale) and the Marie Curie Career Integration Grant (FP7).

\section{References}

Abida WM, Nikolaev A, Zhao W, Zhang W \& Gu W 2007 FBXO11 promotes the Neddylation of p53 and inhibits its transcriptional activity. Journal of Biological Chemistry 282 1797-1804. (doi:10.1074/jbc. M609001200)

Alderton GK 2010 Tumour progression: disease connections. Nature Reviews. Cancer 10 663. (doi:10.1038/nrc2938)

Published by Bioscientifica Ltd. 
Ali SH, Kasper JS, Arai T \& DeCaprio JA 2004 Cul7/p185/p193 binding to simian virus 40 large $\mathrm{T}$ antigen has a role in cellular transformation. Journal of Virology $\mathbf{7 8}$ 2749-2757. (doi:10.1128/JVI.78.6.2749-2757. 2004)

Andrews P, He YJ \& Xiong Y 2006 Cytoplasmic localized ubiquitin ligase cullin 7 binds to p53 and promotes cell growth by antagonizing p53 function. Oncogene 25 4534-4548. (doi:10.1038/sj.onc.1209490)

Aoki I, Higuchi M \& Gotoh Y 2013 NEDDylation controls the target specificity of E2F1 and apoptosis induction. Oncogene 32 3954-3964. (doi:10.1038/onc.2012.428)

Artavanis-Tsakonas K, Misaghi S, Comeaux CA, Catic A, Spooner E, Duraisingh MT \& Ploegh HL 2006 Identification by functional proteomics of a deubiquitinating/deNeddylating enzyme in Plasmodium falciparum. Molecular Microbiology 61 1187-1195. (doi:10.1111/j.1365-2958.2006.05307.x)

Bandau S, Knebel A, Gage ZO, Wood NT \& Alexandru G 2012 UBXN7 docks on neddylated cullin complexes using its UIM motif and causes HIF1 $\alpha$ accumulation. BMC Biology 10 36. (doi:10.1186/ 1741-7007-10-36)

Banks D, Wu M, Higa LA, Gavrilova N, Quan J, Ye T, Kobayashi R, Sun H \& Zhang H 2006 L2DTL/CDT2 and PCNA interact with p53 and regulate p53 polyubiquitination and protein stability through MDM2 and CUL4A/DDB1 complexes. Cell Cycle 5 1719-1729. (doi:10.4161/cc.5. 15.3150)

den Besten W, Verma R, Kleiger G, Oania RS \& Deshaies RJ 2012 NEDD8 links cullin-RING ubiquitin ligase function to the p97 pathway. Nature Structural \& Molecular Biology 19 511-516, S511. (doi:10.1038/nsmb. 2269)

Birol M, Enchev RI, Padilla A, Stengel F, Aebersold R, Betzi S, Yang Y, Hoh F, Peter M, Dumas C et al. 2014 Structural and biochemical characterization of the Cop9 signalosome CSN5/CSN6 heterodimer. PLOS ONE 9 e105688. (doi:10.1371/journal.pone.0105688)

Biswas AK \& Johnson DG 2012 Transcriptional and nontranscriptional functions of E2F1 in response to DNA damage. Cancer Research $\mathbf{7 2}$ 13-17. (doi:10.1158/0008-5472.CAN-11-2196)

Blank JL, Liu XJ, Cosmopoulos K, Bouck DC, Garcia K, Bernard H, Tayber O, Hather G, Liu R, Narayanan U et al. 2013 Novel DNA damage checkpoints mediating cell death induced by the NEDD8-activating enzyme inhibitor MLN4924. Cancer Research 73 225-234. (doi:10.1158/ 0008-5472.CAN-12-1729)

Bloom J, Amador V, Bartolini F, DeMartino G \& Pagano M 2003 Proteasome-mediated degradation of p21 via N-terminal ubiquitinylation. Cell 115 71-82. (doi:10.1016/S0092-8674(03)00755-4)

Boulon S, Westman BJ, Hutten S, Boisvert FM \& Lamond AI 2010 The nucleolus under stress. Molecular Cell 40 216-227. (doi:10.1016/j. molcel.2010.09.024)

Broemer M, Tenev T, Rigbolt KT, Hempel S, Blagoev B, Silke J, Ditzel M \& Meier P 2010 Systematic in vivo RNAi analysis identifies IAPs as NEDD8-E3 ligases. Molecular Cell 40 810-822. (doi:10.1016/j.molcel. 2010.11.011)

Brooks CL \& Gu W 2006 p53 ubiquitination: Mdm2 and beyond. Molecular Cell 21 307-315. (doi:10.1016/j.molcel.2006.01.020)

Brownell JE, Sintchak MD, Gavin JM, Liao H, Bruzzese FJ, Bump NJ, Soucy TA, Milhollen MA, Yang X, Burkhardt AL et al. 2010 Substrateassisted inhibition of ubiquitin-like protein-activating enzymes: the NEDD8 E1 inhibitor MLN4924 forms a NEDD8-AMP mimetic in situ. Molecular Cell 37 102-111. (doi:10.1016/j.molcel.2009.12.024)

Carter S, Bischof O, Dejean A \& Vousden KH 2007 C-terminal modifications regulate MDM2 dissociation and nuclear export of p53. Nature Cell Biology 9 428-435. (doi:10.1038/ncb1562)

Ceccarelli DF, Tang X, Pelletier B, Orlicky S, Xie W, Plantevin V, Neculai D, Chou YC, Ogunjimi A, Al-Hakim A et al. 2011 An allosteric inhibitor of the human Cdc34 ubiquitin-conjugating enzyme. Cell 145 1075-1087. (doi:10.1016/j.cell.2011.05.039)

Chairatvit K \& Ngamkitidechakul C 2007 Control of cell proliferation via elevated NEDD8 conjugation in oral squamous cell carcinoma.
Molecular and Cellular Biochemistry 306 163-169. (doi:10.1007/ s11010-007-9566-7)

Chang L, Zhang Z, Yang J, McLaughlin SH \& Barford D 2014 Molecular architecture and mechanism of the anaphase-promoting complex. Nature 513 388-393. (doi:10.1038/nature13543)

Chen Y, Yang Z, Meng M, Zhao Y, Dong N, Yan H, Liu L, Ding M, Peng HB \& Shao F 2009 Cullin mediates degradation of RhoA through evolutionarily conserved BTB adaptors to control actin cytoskeleton structure and cell movement. Molecular Cell 35 841-855. (doi:10.1016/j.molcel. 2009.09.004)

Choo YS, Vogler G, Wang D, Kalvakuri S, Iliuk A, Tao WA, Bodmer R \& Zhang Z 2012 Regulation of parkin and PINK1 by neddylation. Human Molecular Genetics 21 2514-2523. (doi:10.1093/hmg/dds070)

Cullinan SB, Gordan JD, Jin J, Harper JW \& Diehl JA 2004 The Keap1-BTB protein is an adaptor that bridges Nrf2 to a Cul3-based E3 ligase: oxidative stress sensing by a Cul3-Keap1 ligase. Molecular and Cellular Biology 24 8477-8486. (doi:10.1128/MCB.24.19.8477-8486.2004)

Deshaies RJ, Emberley ED \& Saha A 2010 Control of cullin-ring ubiquitin ligase activity by nedd8. Sub-Cellular Biochemistry $\mathbf{5 4} 41-56$.

Dohmesen C, Koeppel M \& Dobbelstein M 2008 Specific inhibition of Mdm2-mediated neddylation by Tip60. Cell Cycle 7 222-231. (doi:10.4161/cc.7.2.5185)

Duda DM, Borg LA, Scott DC, Hunt HW, Hammel M \& Schulman BA 2008 Structural insights into NEDD8 activation of cullin-RING ligases: conformational control of conjugation. Cell 134 995-1006. (doi:10.1016/j.cell.2008.07.022)

Duda DM, Scott DC, Calabrese MF, Zimmerman ES, Zheng N \& Schulman BA 2011 Structural regulation of cullin-RING ubiquitin ligase complexes. Current Opinion in Structural Biology 21 257-264. (doi:10.1016/j.sbi.2011.01.003)

Duncan K, Schafer G, Vava A, Parker MI \& Zerbini LF 2012 Targeting neddylation in cancer therapy. Future Oncology 8 1461-1470. (doi:10.2217/fon.12.131)

Ebina M, Tsuruta F, Katoh MC, Kigoshi Y, Someya A \& Chiba T 2013 Myeloma overexpressed 2 (Myeov2) regulates L11 subnuclear localization through Nedd8 modification. PLoS ONE 8 e65285. (doi:10.1371/journal.pone.0065285)

Emanuele MJ, Elia AE, Xu Q, Thoma CR, Izhar L, Leng Y, Guo A, Chen YN, Rush J, Hsu PW et al. 2011 Global identification of modular cullin-RING ligase substrates. Cell 147 459-474. (doi:10.1016/j.cell.2011.09.019)

Embade N, Fernandez-Ramos D, Varela-Rey M, Beraza N, Sini M, Gutierrez de Juan V, Woodhoo A, Martinez-Lopez N, Rodriguez-Iruretagoyena B, Bustamante FJ et al. 2012 Murine double minute 2 regulates Hu antigen $\mathrm{R}$ stability in human liver and colon cancer through NEDDylation. Hepatology 55 1237-1248. (doi:10.1002/hep.24795)

Enchev RI, Scott DC, da Fonseca PC, Schreiber A, Monda JK, Schulman BA, Peter M \& Morris EP 2012 Structural basis for a reciprocal regulation between SCF and CSN. Cell Reports 2 616-627. (doi:10.1016/j.celrep. 2012.08.019)

Ferro A, Carvalho AL, Teixeira-Castro A, Almeida C, Tome RJ, Cortes L, Rodrigues AJ, Logarinho E, Sequeiros J, Macedo-Ribeiro S et al. 2007 NEDD8: a new ataxin-3 interactor. Biochimica et Biophysica Acta 1773 1619-1627. (doi:10.1016/j.bbamcr.2007.07.012)

Finley D \& Chau V 1991 Ubiquitination. Annual Review of Cell Biology 7 25-69. (doi:10.1146/annurev.cb.07.110191.000325)

Finley D, Ozkaynak E \& Varshavsky A 1987 The yeast polyubiquitin gene is essential for resistance to high temperatures, starvation, and other stresses. Cell 48 1035-1046. (doi:10.1016/0092-8674(87)90711-2)

Freed E, Lacey KR, Huie P, Lyapina SA, Deshaies RJ, Stearns T \& Jackson PK 1999 Components of an SCF ubiquitin ligase localize to the centrosome and regulate the centrosome duplication cycle. Genes and Development 13 2242-2257. (doi:10.1101/gad.13.17.2242)

Fujiwara M, Marusawa H, Wang HQ, Iwai A, Ikeuchi K, Imai Y, Kataoka A, Nukina N, Takahashi R \& Chiba T 2008 Parkin as a tumor suppressor gene for hepatocellular carcinoma. Oncogene 27 6002-6011. (doi:10.1038/onc.2008.199) 
Gan-Erdene T, Nagamalleswari K, Yin L, Wu K, Pan ZQ \& Wilkinson KD 2003 Identification and characterization of DEN1, a deneddylase of the ULP family. Journal of Biological Chemistry 278 28892-28900. (doi:10.1074/jbc.M302890200)

Gao F, Cheng J, Shi T \& Yeh ET 2006 Neddylation of a breast cancerassociated protein recruits a class III histone deacetylase that represses NFкB-dependent transcription. Nature Cell Biology 8 1171-1177. (doi:10.1038/ncb1483)

Garcia K, Blank JL, Bouck DC, Liu XJ, Sappal DS, Hather G, Cosmopoulos K, Thomas MP, Kuranda M, Pickard MD et al. 2014 Nedd8-activating enzyme inhibitor MLN4924 provides synergy with mitomycin C through Interactions with ATR, BRCA1/BRCA2, and chromatin dynamics pathways. Molecular Cancer Therapeutics 13 1625-1635 (doi:10.1158/1535-7163.MCT-13-0634)

Gastaldello S, Hildebrand S, Faridani O, Callegari S, Palmkvist M, Di Guglielmo C \& Masucci MG 2010 A deneddylase encoded by Epstein-Barr virus promotes viral DNA replication by regulating the activity of cullin-RING ligases. Nature Cell Biology 4 351-361. (doi:10.1038/ncb2035)

Golomb L, Volarevic S \& Oren M 2014 p53 and ribosome biogenesis stress: the essentials. FEBS Letters $\mathbf{5 8 8}$ 2571-2579. (doi:10.1016/j.febslet.2014. 04.014)

Gong L \& Yeh ET 1999 Identification of the activating and conjugating enzymes of the NEDD8 conjugation pathway. Journal of Biological Chemistry 274 12036-12042. (doi:10.1074/jbc.274.17.12036)

Gong L, Kamitani T, Millas S \& Yeh ET 2000 Identification of a novel isopeptidase with dual specificity for ubiquitin- and NEDD8conjugated proteins. Journal of Biological Chemistry 275 14212-14216. (doi:10.1074/jbc.275.19.14212)

Haagenson KK, Tait L, Wang J, Shekhar MP, Polin L, Chen W \& Wu GS 2012 Cullin-3 protein expression levels correlate with breast cancer progression. Cancer Biology \& Therapy 13 1042-1046. (doi:10.4161/ cbt.21046)

Higa LA, Banks D, Wu M, Kobayashi R, Sun H \& Zhang H 2006 L2DTL/CDT2 interacts with the CUL4/DDB1 complex and PCNA and regulates CDT1 proteolysis in response to DNA damage. Cell Cycle $\mathbf{5}$ 1675-1680. (doi:10.4161/cc.5.15.3149)

Hjerpe R, Thomas Y, Chen J, Zemla A, Curran S, Shpiro N, Dick LR \& Kurz T $2012 a$ Changes in the ratio of free NEDD8 to ubiquitin triggers NEDDylation by ubiquitin enzymes. Biochemical Journal 441 927-936. (doi:10.1042/BJ20111671)

Hjerpe R, Thomas Y \& Kurz T 2012b NEDD8 overexpression results in neddylation of ubiquitin substrates by the ubiquitin pathway. Journal of Molecular Biology 421 27-29. (doi:10.1016/j.jmb.2012.05.013)

Hochstrasser M 1998 There's the rub: a novel ubiquitin-like modification linked to cell cycle regulation. Genes and Development 12 901-907. (doi:10.1101/gad.12.7.901)

Hu J, McCall CM, Ohta T \& Xiong Y 2004 Targeted ubiquitination of CDT1 by the DDB1-CUL4A-ROC1 ligase in response to DNA damage. Nature Cell Biology 6 1003-1009. (doi:10.1038/ncb1172)

Huang DT, Miller DW, Mathew R, Cassell R, Holton JM, Roussel MF \& Schulman BA 2004 A unique E1-E2 interaction required for optimal conjugation of the ubiquitin-like protein NEDD8. Nature Structural \& Molecular Biology 11 927-935. (doi:10.1038/nsmb826)

Huang DT, Ayrault O, Hunt HW, Taherbhoy AM, Duda DM, Scott DC, Borg LA, Neale G, Murray PJ, Roussel MF et al. 2009 E2-RING expansion of the NEDD8 cascade confers specificity to cullin modification. Molecular Cell 33 483-495. (doi:10.1016/j.molcel.2009.01.011)

Hurley JH \& Schulman BA 2014 Atomistic autophagy: the structures of cellular self-digestion. Cell 157 300-311. (doi:10.1016/j.cell.2014. 01.070)

Itoh K, Wakabayashi N, Katoh Y, Ishii T, Igarashi K, Engel JD \& Yamamoto M 1999 Keap1 represses nuclear activation of antioxidant responsive elements by Nrf2 through binding to the amino-terminal Neh2 domain. Genes and Development 13 76-86. (doi:10.1101/gad.13.1.76)
Jazaeri AA, Shibata E, Park J, Bryant JL, Conaway MR, Modesitt SC, Smith PG, Milhollen MA, Berger AJ \& Dutta A 2013 Overcoming platinum resistance in preclinical models of ovarian cancer using the neddylation inhibitor MLN4924. Molecular Cancer Therapeutics 12 1958-1967. (doi:10.1158/1535-7163.MCT-12-1028)

Jia L, Li H \& Sun Y 2011 Induction of p21-dependent senescence by an NAE inhibitor, MLN4924, as a mechanism of growth suppression. Neoplasia 13 561-569.

Jin J, Arias EE, Chen J, Harper JW \& Walter JC 2006 A family of diverse Cul4-Ddb1-interacting proteins includes Cdt2, which is required for S phase destruction of the replication factor Cdt1. Molecular Cell $\mathbf{2 3}$ 709-721. (doi:10.1016/j.molcel.2006.08.010)

Kamitani T, Kito K, Nguyen HP \& Yeh ET 1997 Characterization of NEDD8, a developmentally down-regulated ubiquitin-like protein. Journal of Biological Chemistry 272 28557-28562. (doi:10.1074/jbc. 272.45.28557)

Kamitani T, Kito K, Fukuda-Kamitani T \& Yeh ET 2001 Targeting of NEDD8 and its conjugates for proteasomal degradation by NUB1. Journal of Biological Chemistry 276 46655-46660. (doi:10.1074/jbc.M108636200)

Kamura T, Conrad MN, Yan Q, Conaway RC \& Conaway JW 1999a The Rbx1 subunit of SCF and VHL E3 ubiquitin ligase activates Rub1 modification of cullins Cdc53 and Cul2. Genes and Development 13 2928-2933. (doi:10.1101/gad.13.22.2928)

Kamura T, Koepp DM, Conrad MN, Skowyra D, Moreland RJ, Iliopoulos O, Lane WS, Kaelin WG Jr, Elledge SJ, Conaway RC et al. 1999b Rbx1, a component of the VHL tumor suppressor complex and SCF ubiquitin ligase. Science $\mathbf{2 8 4}$ 657-661. (doi:10.1126/science.284.5414.657)

Karin M \& Ben-Neriah Y 2000 Phosphorylation meets ubiquitination: the control of NF-кB activity. Annual Review of Immunology 18 621-663. (doi:10.1146/annurev.immunol.18.1.621)

Kee Y, Huang M, Chang S, Moreau LA, Park E, Smith PG \& D'Andrea AD 2012 Inhibition of the Nedd8 system sensitizes cells to DNA interstrand cross-linking agents. Molecular Cancer Research 10 369-377. (doi:10.1158/1541-7786.MCR-11-0497)

Kelsall IR, Duda DM, Olszewski JL, Hofmann K, Knebel A, Langevin F, Wood N, Wightman M, Schulman BA \& Alpi AF 2013 TRIAD1 and HHARI bind to and are activated by distinct neddylated cullin-RING ligase complexes. EMBO Journal 32 2848-2860. (doi:10.1038/emboj. 2013.209)

Kim Y \& Kipreos ET 2007 Cdt1 degradation to prevent DNA re-replication: conserved and non-conserved pathways. Cell Division 218. (doi:10.1186/1747-1028-2-18)

Kim SS, Shago M, Kaustov L, Boutros PC, Clendening JW, Sheng Y, Trentin GA, Barsyte-Lovejoy D, Mao DY, Kay R et al. 2007 CUL7 is a novel antiapoptotic oncogene. Cancer Research 67 9616-9622. (doi:10.1158/ 0008-5472.CAN-07-0644)

Kim W, Bennett EJ, Huttlin EL, Guo A, Li J, Possemato A, Sowa ME, Rad R, Rush J, Comb MJ et al. 2011 Systematic and quantitative assessment of the ubiquitin-modified proteome. Molecular Cell 44 325-340. (doi:10.1016/j.molcel.2011.08.025)

Kito K, Yeh ET \& Kamitani T 2001 NUB1, a NEDD8-interacting protein, is induced by interferon and down-regulates the NEDD8 expression. Journal of Biological Chemistry 276 20603-20609. (doi:10.1074/ jbc.M100920200)

Koepp DM, Schaefer LK, Ye X, Keyomarsi K, Chu C, Harper JW \& Elledge SJ 2001 Phosphorylation-dependent ubiquitination of cyclin $\mathrm{E}$ by the SCFFbw7 ubiquitin ligase. Science 294 173-177. (doi:10.1126/ science.1065203)

Komarov PG, Komarova EA, Kondratov RV, Christov-Tselkov K, Coon JS, Chernov MV \& Gudkov AV 1999 A chemical inhibitor of p53 that protects mice from the side effects of cancer therapy. Science $\mathbf{2 8 5}$ 1733-1737. (doi:10.1126/science.285.5434.1733)

Kondo K \& Kaelin WG Jr 2001 The von Hippel-Lindau tumor suppressor gene. Experimental Cell Research 264 117-125. (doi:10.1006/ excr.2000.5139) http://erc.endocrinology-journals.org

DOI: 10.1530/ERC-14-0315
(C) 2015 Society for Endocrinology Printed in Great Britain 
Kumar S, Yoshida Y \& Noda M 1993 Cloning of a cDNA which encodes a novel ubiquitin-like protein. Biochemical and Biophysical Research Communications 195 393-399. (doi:10.1006/bbrc.1993.2056)

Kurz T, Chou YC, Willems AR, Meyer-Schaller N, Hecht ML, Tyers M, Peter M \& Sicheri F 2008 Dcn1 functions as a scaffold-type E3 ligase for cullin neddylation. Molecular Cell 29 23-35. (doi:10.1016/j.molcel. 2007.12.012)

Kwon J, Wang YL, Setsuie R, Sekiguchi S, Sato Y, Sakurai M, Noda M, Aoki S, Yoshikawa Y \& Wada K 2004 Two closely related ubiquitin C-terminal hydrolase isozymes function as reciprocal modulators of germ cell apoptosis in cryptorchid testis. American Journal of Pathology 165 1367-1374. (doi:10.1016/S0002-9440(10)63394-9)

Lammer D, Mathias N, Laplaza JM, Jiang W, Liu Y, Callis J, Goebl M \& Estelle M 1998 Modification of yeast Cdc53p by the ubiquitin-related protein rub1p affects function of the SCFCdc4 complex. Genes and Development 12 914-926. (doi:10.1101/gad.12.7.914)

Lane DP 2012 Stress, specificity and the NEDD8 proteome. Cell Cycle $\mathbf{1 1}$ 1488-1489. (doi:10.4161/cc.20073)

Leck YC, Choo YY, Tan CY, Smith PG \& Hagen T 2010 Biochemical and cellular effects of inhibiting Nedd8 conjugation. Biochemical and Biophysical Research Communications 398 588-593. (doi:10.1016/j.bbrc. 2010.06.128)

Lee J \& Zhou P 2010 Cullins and cancer. Genes \& Cancer 1 690-699. (doi:10.1177/1947601910382899)

Lee MR, Lee D, Shin SK, Kim YH \& Choi CY 2008 Inhibition of APP intracellular domain (AICD) transcriptional activity via covalent conjugation with Nedd8. Biochemical and Biophysical Research Communications 366 976-981. (doi:10.1016/j.bbrc.2007.12.066)

Lee YJ, Johnson KR \& Hallenbeck JM 2012 Global protein conjugation by ubiquitin-like-modifiers during ischemic stress is regulated by microRNAs and confers robust tolerance to ischemia. PLOS ONE 7 e47787. (doi:10.1371/journal.pone.0047787)

Leidecker O, Matic I, Mahata B, Pion E \& Xirodimas DP 2012 The ubiquitin E1 enzyme Ube1 mediates NEDD8 activation under diverse stress conditions. Cell Cycle 11 1142-1150. (doi:10.4161/cc. 11.6.19559)

Leyser HM, Lincoln CA, Timpte C, Lammer D, Turner J \& Estelle M 1993 Arabidopsis auxin-resistance gene AXR1 encodes a protein related to ubiquitin-activating enzyme E1. Nature 364 161-164. (doi:10.1038/ 364161a0)

Li W \& Kong AN 2009 Molecular mechanisms of Nrf2-mediated antioxidant response. Molecular Carcinogenesis 48 91-104. (doi:10. 1002/mc.20465)

Li T, Guan J, Huang Z, Hu X \& Zheng X 2014a RNF168-mediated H2A neddylation antagonizes ubiquitylation of $\mathrm{H} 2 \mathrm{~A}$ and regulates DNA damage repair. Journal of Cell Science 127 2238-2248. (doi:10.1242/jcs. 138891)

Li H, Tan M, Jia L, Wei D, Zhao Y, Chen G, Xu J, Zhao L, Thomas D, Beer DG et al. 2014b Inactivation of SAG/RBX2 E3 ubiquitin ligase suppresses KrasG12D-driven lung tumorigenesis. Journal of Clinical Investigation 124 835-846. (doi:10.1172/JCI70297)

Li L, Wang M, Yu G, Chen P, Li H, Wei D, Zhu J, Xie L, Jia H, Shi J et al. 2014 c Overactivated neddylation pathway as a therapeutic target in lung cancer. Journal of the National Cancer Institute 106 dju083. (doi:10.1093/ jnci/dju083)

Liakopoulos D, Doenges G, Matuschewski K \& Jentsch S 1998 A novel protein modification pathway related to the ubiquitin system. EMBO Journal 17 2208-2214. (doi:10.1093/emboj/17.8.2208)

Lin JJ, Milhollen MA, Smith PG, Narayanan U \& Dutta A 2010 NEDD8-targeting drug MLN4924 elicits DNA rereplication by stabilizing Cdt1 in S phase, triggering checkpoint activation, apoptosis, and senescence in cancer cells. Cancer Research 70 10310-10320. (doi:10.1158/0008-5472.CAN-10-2062)

Lingaraju GM, Bunker RD, Cavadini S, Hess D, Hassiepen U, Renatus M, Fischer ES \& Thoma NH 2014 Crystal structure of the human COP9 signalosome. Nature 512 161-165. (doi:10.1038/nature13566)

http://erc.endocrinology-journals.org DOI: 10.1530/ERC-14-0315
(C) 2015 Society for Endocrinology Printed in Great Britain
Linghu B, Callis J \& Goebl MG 2002 Rub1p processing by Yuh1p is required for wild-type levels of Rub1p conjugation to Cdc53p. Eukaryotic Cell $\mathbf{1}$ 491-494. (doi:10.1128/EC.1.3.491-494.2002)

Liu G \& Xirodimas DP 2010 NUB1 promotes cytoplasmic localization of p53 through cooperation of the NEDD8 and ubiquitin pathways. Oncogene 29 2252-2261. (doi:10.1038/onc.2009.494)

Loftus SJ, Liu G, Carr SM, Munro S \& La Thangue NB 2012 NEDDylation regulates E2F-1-dependent transcription. EMBO Reports 13 811-818. (doi:10.1038/embor.2012.113)

Luo Z, Pan Y, Jeong LS, Liu J \& Jia L $2012 a$ Inactivation of the cullin (CUL)RING E3 ligase by the NEDD8-activating enzyme inhibitor MLN4924 triggers protective autophagy in cancer cells. Autophagy 8 1677-1679. (doi:10.4161/auto.21484)

Luo Z, Yu G, Lee HW, Li L, Wang L, Yang D, Pan Y, Ding C, Qian J, Wu L et al. $2012 b$ The Nedd8-activating enzyme inhibitor MLN4924 induces autophagy and apoptosis to suppress liver cancer cell growth. Cancer Research 72 3360-3371. (doi:10.1158/0008-5472.CAN-12-0388)

Lyapina S, Cope G, Shevchenko A, Serino G, Tsuge T, Zhou C, Wolf DA, Wei N, Shevchenko A \& Deshaies RJ 2001 Promotion of NEDD-CUL1 conjugate cleavage by COP9 signalosome. Science 292 1382-1385. (doi:10.1126/science.1059780)

Ma T, Chen Y, Zhang F, Yang CY, Wang S \& Yu X 2013 RNF111-dependent neddylation activates DNA damage-induced ubiquitination. Molecular Cell 49 897-907. (doi:10.1016/j.molcel.2013.01.006)

Mahata B, Sundqvist A \& Xirodimas DP 2012 Recruitment of RPL11 at promoter sites of p53-regulated genes upon nucleolar stress through NEDD8 and in an Mdm2-dependent manner. Oncogene 31 3060-3071. (doi:10.1038/onc.2011.482)

Massagué J, Blain SW \& Lo RS 2000 TGF $\beta$ signaling in growth control, cancer, and heritable disorders. Cell 103 295-309. (doi:10.1016/00928674(00)00121-5)

Mendoza HM, Shen LN, Botting C, Lewis A, Chen J, Ink B \& Hay RT 2003 NEDP1, a highly conserved cysteine protease that deNEDDylates cullins. Journal of Biological Chemistry 278 25637-25643. (doi:10.1074/ jbc.M212948200)

Merlet J, Burger J, Gomes JE \& Pintard L 2009 Regulation of cullin-RING E3 ubiquitin-ligases by neddylation and dimerization. Cellular and Molecular Life Sciences 66 1924-1938. (doi:10.1007/s00018-0098712-7)

Milhollen MA, Traore T, Adams-Duffy J, Thomas MP, Berger AJ, Dang L, Dick LR, Garnsey JJ, Koenig E, Langston SP et al. 2010 MLN4924, a NEDD8-activating enzyme inhibitor, is active in diffuse large B-cell lymphoma models: rationale for treatment of NF- $\{\kappa\} B-d e p e n d e n t$ lymphoma. Blood 116 1515-1523. (doi:10.1182/blood-2010-03272567)

Milhollen MA, Thomas MP, Narayanan U, Traore T, Riceberg J, Amidon BS Bence NF, Bolen JB, Brownell J, Dick LR et al. 2012 Treatment-emergent mutations in NAE $\beta$ confer resistance to the NEDD8-activating enzyme inhibitor MLN4924. Cancer Cell 21 388-401. (doi:10.1016/j.ccr.2012. 02.009)

Muller PA \& Vousden KH 2014 Mutant p53 in cancer: new functions and therapeutic opportunities. Cancer Cell 25 304-317. (doi:10.1016/j.ccr. 2014.01.021)

Nag A, Bagchi S \& Raychaudhuri P 2004 Cul4A physically associates with MDM2 and participates in the proteolysis of p53. Cancer Research 64 8152-8155. (doi:10.1158/0008-5472.CAN-04-2598)

Nagano T, Hashimoto T, Nakashima A, Kikkawa U \& Kamada S 2012 Xlinked inhibitor of apoptosis protein mediates neddylation by itself but does not function as a NEDD8-E3 ligase for caspase-7. FEBS Letters $\mathbf{5 8 6}$ 1612-1616. (doi:10.1016/j.febslet.2012.04.056)

Nikolaev AY, Li M, Puskas N, Qin J \& Gu W 2003 Parc: a cytoplasmic anchor for p53. Cell 112 29-40. (doi:10.1016/S0092-8674(02)01255-2)

Noguchi K, Okumura F, Takahashi N, Kataoka A, Kamiyama T, Todo S \& Hatakeyama S 2011 TRIM40 promotes neddylation of IKK $\gamma$ and is downregulated in gastrointestinal cancers. Carcinogenesis 32 995-1004. (doi:10.1093/carcin/bgr068) 
Ohh M 2006 Ubiquitin pathway in VHL cancer syndrome. Neoplasia 8 623-629. (doi:10.1593/neo.06442)

Ohh M, Kim WY, Moslehi JJ, Chen Y, Chau V, Read MA \& Kaelin WG Jr 2002 An intact NEDD8 pathway is required for cullin-dependent ubiquitylation in mammalian cells. EMBO Reports 3 177-182. (doi:10.1093/embo-reports/kvf028)

Osaka F, Kawasaki H, Aida N, Saeki M, Chiba T, Kawashima S, Tanaka K \& Kato S 1998 A new NEDD8-ligating system for cullin-4A. Genes and Development 12 2263-2268. (doi:10.1101/gad.12.15.2263)

Oved S, Mosesson Y, Zwang Y, Santonico E, Shtiegman K, Marmor MD, Kochupurakkal BS, Katz M, Lavi S, Cesareni G et al. 2006 Conjugation to Nedd8 instigates ubiquitylation and down-regulation of activated receptor tyrosine kinases. Journal of Biological Chemistry $\mathbf{2 8 1}$ 21640-21651. (doi:10.1074/jbc.M513034200)

Pan ZQ, Kentsis A, Dias DC, Yamoah K \& Wu K 2004 Nedd8 on cullin: building an expressway to protein destruction. Oncogene 23 1985-1997. (doi:10.1038/sj.onc.1207414)

Perkins ND 2012 The diverse and complex roles of NF-кB subunits in cancer. Nature Reviews. Cancer 12 121-132. (doi:10.1038/nrc3204)

Picchio MC, Martin ES, Cesari R, Calin GA, Yendamuri S, Kuroki T, Pentimalli F, Sarti M, Yoder K, Kaiser LR et al. 2004 Alterations of the tumor suppressor gene Parkin in non-small cell lung cancer. Clinical Cancer Research 10 2720-2724. (doi:10.1158/1078-0432.CCR03-0086)

Pierce NW, Lee JE, Liu X, Sweredoski MJ, Graham RL, Larimore EA, Rome M, Zheng N, Clurman BE, Hess S et al. 2013 Cand1 promotes assembly of new SCF complexes through dynamic exchange of F box proteins. Cell 153 206-215. (doi:10.1016/j.cell.2013.02.024)

Pozo JC, Timpte C, Tan S, Callis J \& Estelle M 1998 The ubiquitin-related protein RUB1 and auxin response in Arabidopsis. Science $\mathbf{2 8 0}$ 1760-1763. (doi:10.1126/science.280.5370.1760)

Querido E, Blanchette P, Yan Q, Kamura T, Morrison M, Boivin D, Kaelin WG, Conaway RC, Conaway JW \& Branton PE 2001 Degradation of p53 by adenovirus E4orf6 and E1B55K proteins occurs via a novel mechanism involving a cullin-containing complex. Genes and Development 15 3104-3117. (doi:10.1101/gad.926401)

Rabut G \& Peter M 2008 Function and regulation of protein neddylation. 'Protein modifications: beyond the usual suspects' review series. EMBO Reports 9 969-976. (doi:10.1038/embor.2008.183)

Rabut G, Le Dez G, Verma R, Makhnevych T, Knebel A, Kurz T, Boone C, Deshaies RJ \& Peter M 2011 The TFIIH subunit Tfb3 regulates cullin neddylation. Molecular Cell 43 488-495. (doi:10.1016/j.molcel. 2011.05.032)

Renaudin X, Guervilly JH, Aoufouchi S \& Rosselli F 2014 Proteomic analysis reveals a FANCA-modulated neddylation pathway involved in CXCR5 membrane targeting and cell mobility. Journal of Cell Science $\mathbf{1 2 7}$ 3546-3554. (doi:10.1242/jcs.150706)

Russell RC \& Ohh M 2008 NEDD8 acts as a 'molecular switch' defining the functional selectivity of VHL. EMBO Reports 9 486-491. (doi:10.1038/ embor.2008.19)

Saha A \& Deshaies RJ 2008 Multimodal activation of the ubiquitin ligase SCF by Nedd8 conjugation. Molecular Cell 32 21-31. (doi:10.1016/j. molcel.2008.08.021)

Salon C, Brambilla E, Brambilla C, Lantuejoul S, Gazzeri S \& Eymin B 2007 Altered pattern of Cul-1 protein expression and neddylation in human lung tumours: relationships with CAND1 and cyclin E protein levels. Journal of Pathology 213 303-310. (doi:10.1002/path.2223)

Sansam CL, Shepard JL, Lai K, Ianari A, Danielian PS, Amsterdam A, Hopkins N \& Lees JA 2006 DTL/CDT2 is essential for both CDT1 regulation and the early G2/M checkpoint. Genes and Development 20 3117-3129. (doi:10.1101/gad.1482106)

Sarkaria I, Oc P, Talbot SG, Reddy PG, Ngai I, Maghami E, Patel KN, Lee B, Yonekawa Y, Dudas M et al. 2006 Squamous cell carcinoma related oncogene/DCUN1D1 is highly conserved and activated by amplification in squamous cell carcinomas. Cancer Research 66 9437-9444. (doi:10.1158/0008-5472.CAN-06-2074)
Sato Y, Kamura T, Shirata N, Murata T, Kudoh A, Iwahori S, Nakayama S, Isomura $\mathrm{H}$, Nishiyama $\mathrm{Y} \&$ Tsurumi T 2009 Degradation of phosphorylated p53 by viral protein-ECS E3 ligase complex. PLoS Pathogens 5 e1000530. (doi:10.1371/journal.ppat.1000530)

Schreiber A \& Peter M 2014 Substrate recognition in selective autophagy and the ubiquitin-proteasome system. Biochimica et Biophysica Acta 1843 163-181. (doi:10.1016/j.bbamcr.2013.03.019)

Schreiber A, Stengel F, Zhang Z, Enchev RI, Kong EH, Morris EP, Robinson CV, da Fonseca PC \& Barford D 2011 Structural basis for the subunit assembly of the anaphase-promoting complex. Nature 470 227-232. (doi:10.1038/nature09756)

Scott DC, Monda JK, Bennett EJ, Harper JW \& Schulman BA 2011 Nterminal acetylation acts as an avidity enhancer within an interconnected multiprotein complex. Science 334 674-678. (doi:10.1126/ science.1209307)

Scott DC, Sviderskiy VO, Monda JK, Lydeard JR, Cho SE, Harper JW \& Schulman BA 2014 Structure of a RING E3 trapped in action reveals ligation mechanism for the ubiquitin-like protein NEDD8. Cell 157 1671-1684. (doi:10.1016/j.cell.2014.04.037)

Senga T, Sivaprasad U, Zhu W, Park JH, Arias EE, Walter JC \& Dutta A 2006 PCNA is a cofactor for Cdt1 degradation by CUL4/DDB1-mediated N-terminal ubiquitination. Journal of Biological Chemistry 281 6246-6252. (doi:10.1074/jbc.M512705200)

Shen LN, Liu H, Dong C, Xirodimas D, Naismith JH \& Hay RT 2005 Structural basis of NEDD8 ubiquitin discrimination by the deNEDDylating enzyme NEDP1. EMBO Journal 24 1341-1351. (doi:10.1038/ sj.emboj.7600628)

Singh RK, Zerath S, Kleifeld O, Scheffner M, Glickman MH \& Fushman D 2012 Recognition and cleavage of related to ubiquitin 1 (Rub1) and Rub1-ubiquitin chains by components of the ubiquitin-proteasome system. Molecular \& Cellular Proteomics 11 1595-1611. (doi:10.1074/ mcp.M112.022467)

Singh RK, Sundar A \& Fushman D 2014 Nonenzymatic rubylation and ubiquitination of proteins for structural and functional studies. Angewandte Chemie (International ed. in English) 53 6120-6125. (doi:10.1002/anie.201402642)

Skaar JR \& Pagano M 2009 Control of cell growth by the SCF and APC/C ubiquitin ligases. Current Opinion in Cell Biology 21 816-824. (doi:10.1016/j.ceb.2009.08.004)

Skaar JR, Florens L, Tsutsumi T, Arai T, Tron A, Swanson SK, Washburn MP \& DeCaprio JA 2007 PARC and CUL7 form atypical cullin RING ligase complexes. Cancer Research 67 2006-2014. (doi:10.1158/0008-5472. CAN-06-3241)

Skowyra D, Koepp DM, Kamura T, Conrad MN, Conaway RC, Conaway JW, Elledge SJ \& Harper JW 1999 Reconstitution of G1 cyclin ubiquitination with complexes containing SCFGrr1 and Rbx1. Science 284 662-665. (doi:10.1126/science.284.5414.662)

Soucy TA, Smith PG, Milhollen MA, Berger AJ, Gavin JM, Adhikari S, Brownell JE, Burke KE, Cardin DP, Critchley S et al. 2009 An inhibitor of NEDD8-activating enzyme as a new approach to treat cancer. Nature 458 732-736. (doi:10.1038/nature07884)

Soucy TA, Dick LR, Smith PG, Milhollen MA \& Brownell JE 2010 The NEDD8 conjugation pathway and Its relevance in cancer biology and therapy. Genes \& Cancer 1 708-716. (doi:10.1177) 1947601910382898)

Stickle NH, Chung J, Klco JM, Hill RP, Kaelin WG Jr \& Ohh M 2004 pVHL modification by NEDD8 is required for fibronectin matrix assembly and suppression of tumor development. Molecular and Cellular Biology 24 3251-3261. (doi:10.1128/MCB.24.8.3251-3261.2004)

Sundqvist A, Liu G, Mirsaliotis A \& Xirodimas DP 2009 Regulation of nucleolar signalling to p53 through NEDDylation of L11. EMBO Reports 10 1132-1139. (doi:10.1038/embor.2009.178)

Swords RT, Kelly KR, Smith PG, Garnsey JJ, Mahalingam D, Medina E, Oberheu K, Padmanabhan S, O'Dwyer M, Nawrocki ST et al. 2010 Inhibition of NEDD8-activating enzyme: a novel approach for the 
treatment of acute myeloid leukemia. Blood 115 3796-3800. (doi:10.1182/blood-2009-11-254862)

Takashima O, Tsuruta F, Kigoshi Y, Nakamura S, Kim J, Katoh MC, Fukuda T, Irie $\mathrm{K} \&$ Chiba T 2013 Brap2 regulates temporal control of NF- $\mathrm{kB}$ localization mediated by inflammatory response. PLOS ONE 8 e58911. (doi:10.1371/journal.pone.0058911)

Tan M, Li H \& Sun Y 2013 Endothelial deletion of Sag/Rbx2/Roc2 E3 ubiquitin ligase causes embryonic lethality and blocks tumor angiogenesis. Oncogene 33 5211-5220. (doi:10.1038/onc.2013.473)

Tetzlaff MT, Yu W, Li M, Zhang P, Finegold M, Mahon K, Harper JW, Schwartz RJ \& Elledge SJ 2004 Defective cardiovascular development and elevated cyclin $\mathrm{E}$ and Notch proteins in mice lacking the Fbw7 F-box protein. PNAS 101 3338-3345. (doi:10.1073/pnas. 0307875101)

Thirunavukarasou A, Singh P, Govindarajalu G, Bandi V \& Baluchamy S 2014 E3 ubiquitin ligase Cullin4B mediated polyubiquitination of p53 for its degradation. Molecular and Cellular Biochemistry 390 93-100. (doi:10.1007/s11010-014-1960-3)

Toth JI, Yang L, Dahl R \& Petroski MD 2012 A gatekeeper residue for NEDD8-activating enzyme inhibition by MLN4924. Cell Reports 1 309-316. (doi:10.1016/j.celrep.2012.02.006)

Um JW, Han KA, Im E, Oh Y, Lee K \& Chung KC 2012 Neddylation positively regulates the ubiquitin E3 ligase activity of parkin. Journal of Neuroscience Research 90 1030-1042. (doi:10.1002/jnr.22828)

Vlatkovic N, Boyd MT \& Rubbi CP 2014 Nucleolar control of p53: a cellular Achilles' heel and a target for cancer therapy. Cellular and Molecular Life Sciences 71 771-791. (doi:10.1007/s00018-013-1361-x)

Wada H, Kito K, Caskey LS, Yeh ET \& Kamitani T 1998 Cleavage of the C-terminus of NEDD8 by UCH-L3. Biochemical and Biophysical Research Communications 251 688-692. (doi:10.1006/bbrc.1998.9532)

Walden H, Podgorski MS, Huang DT, Miller DW, Howard RJ, Minor DL Jr, Holton JM \& Schulman BA 2003a The structure of the APPBP1UBA3-NEDD8-ATP complex reveals the basis for selective ubiquitin-like protein activation by an E1. Molecular Cell 12 1427-1437. (doi:10.1016/ S1097-2765(03)00452-0)

Walden H, Podgorski MS \& Schulman BA 2003b Insights into the ubiquitin transfer cascade from the structure of the activating enzyme for NEDD8. Nature 422 330-334. (doi:10.1038/nature01456)

Wang M, Medeiros BC, Erba HP, DeAngelo DJ, Giles FJ \& Swords RT 2011 Targeting protein neddylation: a novel therapeutic strategy for the treatment of cancer. Expert Opinion on Therapeutic Targets 15 253-264. (doi:10.1517/14728222.2011.550877)

Wang Z, Liu P, Inuzuka H \& Wei W 2014 Roles of F-box proteins in cancer. Nature Reviews. Cancer 14 233-247. (doi:10.1038/nrc3700)

Watson IR, Blanch A, Lin DC, Ohh M \& Irwin MS 2006 Mdm2-mediated NEDD8 modification of TAp73 regulates its transactivation function. Journal of Biological Chemistry 281 34096-34103. (doi:10.1074/jbc. M603654200)

Watson IR, Irwin MS \& Ohh M 2011 NEDD8 pathways in cancer, Sine Quibus Non. Cancer Cell 19 168-176. (doi:10.1016/j.ccr.2011.01.002)

Wei D, Li H, Yu J, Sebolt JT, Zhao L, Lawrence TS, Smith PG, Morgan MA \& Sun Y 2012 Radiosensitization of human pancreatic cancer cells by MLN4924, an investigational NEDD8-activating enzyme inhibitor. Cancer Research 72 282-293. (doi:10.1158/0008-5472. CAN-11-2866)

Welcker M \& Clurman BE 2008 FBW7 ubiquitin ligase: a tumour suppressor at the crossroads of cell division, growth and differentiation. Nature Reviews. Cancer 8 83-93. (doi:10.1038/nrc2290)

Welcker M, Singer J, Loeb KR, Grim J, Bloecher A, Gurien-West M, Clurman BE \& Roberts JM 2003 Multisite phosphorylation by Cdk2 and GSK3 controls cyclin E degradation. Molecular Cell 12 381-392. (doi:10.1016/ S1097-2765(03)00287-9)

Whitby FG, Xia G, Pickart CM \& Hill CP 1998 Crystal structure of the human ubiquitin-like protein NEDD8 and interactions with ubiquitin pathway enzymes. Journal of Biological Chemistry 273 34983-34991. (doi:10.1074/jbc.273.52.34983)
Wu K, Yamoah K, Dolios G, Gan-Erdene T, Tan P, Chen A, Lee CG, Wei N, Wilkinson KD, Wang R et al. 2003 DEN1 is a dual function protease capable of processing the $\mathrm{C}$ terminus of Nedd8 and deconjugating hyper-neddylated CUL1. Journal of Biological Chemistry $\mathbf{2 7 8}$ 28882-28891. (doi:10.1074/jbc.M302888200)

Wu S, Zhu W, Nhan T, Toth JI, Petroski MD \& Wolf DA 2013 CAND1 controls in vivo dynamics of the cullin 1-RING ubiquitin ligase repertoire. Nature Communications 4 1642. (doi:10.1038/ ncomms2636)

Xie P, Zhang M, He S, Lu K, Chen Y, Xing G, Lu Y, Liu P, Li Y, Wang S et al. 2014 The covalent modifier Nedd8 is critical for the activation of Smurf1 ubiquitin ligase in tumorigenesis. Nature Communications 5 3733. (doi:10.1038/ncomms4733)

Xirodimas DP 2008 Novel substrates and functions for the ubiquitin-like molecule NEDD8. Biochemical Society Transactions 36 802-806. (doi:10.1042/BST0360802)

Xirodimas DP, Saville MK, Bourdon JC, Hay RT \& Lane DP 2004 Mdm2mediated NEDD8 conjugation of p53 inhibits its transcriptional activity. Cell 118 83-97. (doi:10.1016/j.cell.2004.06.016)

Xirodimas DP, Sundqvist A, Nakamura A, Shen L, Botting C \& Hay RT 2008 Ribosomal proteins are targets for the NEDD8 pathway. EMBO Reports 9 280-286. (doi:10.1038/embor.2008.10)

Xu GW, Toth JI, da Silva SR, Paiva SL, Lukkarila JL, Hurren R, Maclean N, Sukhai MA, Bhattacharjee RN, Goard CA et al. 2014 Mutations in UBA3 confer resistance to the NEDD8-activating enzyme inhibitor MLN4924 in human leukemic cells. PLOS ONE 9 e93530. (doi:10.1371/journal. pone.0093530)

Yang Y, Kitagaki J, Dai RM, Tsai YC, Lorick KL, Ludwig RL, Pierre SA, Jensen JP, Davydov IV, Oberoi P et al. 2007a Inhibitors of ubiquitin-activating enzyme (E1), a new class of potential cancer therapeutics. Cancer Research 67 9472-9481. (doi:10.1158/0008-5472. CAN-07-0568)

Yang X, Zhou J, Sun L, Wei Z, Gao J, Gong W, Xu RM, Rao Z \& Liu Y 2007 b Structural basis for the function of DCN-1 in protein Neddylation. Journal of Biological Chemistry 282 24490-24494. (doi:10.1074/jbc. C700038200)

Yang ZJ, Chee CE, Huang S \& Sinicrope FA 2011 The role of autophagy in cancer: therapeutic implications. Molecular Cancer Therapeutics 10 1533-1541. (doi:10.1158/1535-7163)

Yang D, Tan M, Wang G \& Sun Y 2012a The p21-dependent radiosensitization of human breast cancer cells by MLN4924, an investigational inhibitor of NEDD8 activating enzyme. PLoS ONE 7 e34079. (doi:10.1158/1535-7163.MCT-11-0047)

Yang D, Zhao Y, Liu J, Sun Y \& Jia L 2012b Protective autophagy induced by RBX1/ROC1 knockdown or CRL inactivation via modulating the DEPTOR-MTOR axis. Autophagy 8 1856-1858. (doi:10.1371/journal. pone.0034079)

Yao WT, Wu JF, Yu GY, Wang R, Wang K, Li LH, Chen P, Jiang YN, Cheng H, Lee HW et al. 2014 Suppression of tumor angiogenesis by targeting the protein Neddylation pathway. Cell Death \& Disease 5 e1059. (doi:10.1038/cddis.2014.21)

Ye Y, Akutsu M, Reyes-Turcu F, Enchev RI, Wilkinson KD \& Komander D 2011 Polyubiquitin binding and cross-reactivity in the USP domain deubiquitinase USP21. EMBO Reports 12 350-357. (doi:10.1038/embor. 2011.17)

Zemla A, Thomas Y, Kedziora S, Knebel A, Wood NT, Rabut G \& Kurz T 2013 CSN- and CAND1-dependent remodelling of the budding yeast SCF complex. Nature Communications 4 1641. (doi:10.1038/ ncomms2628)

Zhang Y \& Lu H 2009 Signaling to p53: ribosomal proteins find their way. Cancer Cell 16 369-377. (doi:10.1016/j.ccr.2009.09.024)

Zhang J, Bai D, Ma X, Guan J \& Zheng X 2014 hCINAP is a novel regulator of ribosomal protein-HDM2-p53 pathway by controlling NEDDylation of ribosomal protein S14. Oncogene 33 246-254. (doi:10.1038/onc. 2012.560) 
Zhao Y \& Sun Y 2013 Cullin-RING ligases as attractive anti-cancer targets. Current Pharmaceutical Design 19 3215-3225. (doi:10.2174/ 13816128113199990300)

Zhao L, Yue P, Lonial S, Khuri FR \& Sun SY 2011 The NEDD8-activating enzyme inhibitor, MLN4924, cooperates with TRAIL to augment apoptosis through facilitating c-FLIP degradation in head and neck cancer cells. Molecular Cancer Therapeutics 10 2415-2425. (doi:10.1158/ 1535-7163.MCT-11-0401)

Zhao Y, Xiong X, Jia L \& Sun Y 2012 Targeting cullin-RING ligases by MLN4924 induces autophagy via modulating the HIF1-REDD1-TSC1-mTORC1DEPTOR axis. Cell Death \& Disease 3 e386. (doi:10.1038/cddis.2012.125)
Zhong W, Feng H, Santiago FE \& Kipreos ET 2003 CUL-4 ubiquitin ligase maintains genome stability by restraining DNA-replication licensing. Nature 423 885-889. (doi:10.1038/nature01747)

Zhou C, Seibert V, Geyer R, Rhee E, Lyapina S, Cope G, Deshaies RJ \& Wolf DA 2001 The fission yeast COP9/signalosome is involved in cullin modification by ubiquitin-related Ned8p. BMC Biochemistry 27. (doi:10.1186/1471-2091-2-7)

Zuo W, Huang F, Chiang YJ, Li M, Du J, Ding Y, Zhang T, Lee HW, Jeong LS, Chen Y et al. 2013 c-Cbl-mediated neddylation antagonizes ubiquitination and degradation of the TGF- $\beta$ type II receptor. Molecular Cell 49 499-510. (doi:10.1016/j.molcel.2012.12.002)

Received in final form 19 November 2014

Accepted 11 December 2014

Made available online as an Accepted Preprint

11 December 2014
Published by Bioscientifica Ltd. 